\title{
Wind-Driven Oceanic Rossby Waves in the Tropical South Indian Ocean with and without an Active ENSO
}

\author{
ASTRID BAQUERO-BERNAL \\ Max-Planck Institut für Meteorologie, Hamburg, Germany \\ MojiB LATIF \\ Leibniz-Institut für Meereswissenschaften, Kiel, Germany
}

(Manuscript received 20 March 2004, in final form 9 September 2004)

\begin{abstract}
The interannual heat content variability in the tropical south Indian Ocean (SIO) and its relationship with El Niño-Southern Oscillation (ENSO) is studied. The baroclinic ocean response to stochastic wind stress predicted by a simple analytical model is compared with two integrations of the ECHO-G coupled general circulation model. In one integration, ocean-atmosphere interactions are suppressed in the tropical Pacific Ocean, so that this integration does not simulate ENSO. In the other integration, interactions are allowed everywhere and ENSO is simulated. The results show that basinwide variability in the SIO heat content can be produced by two mechanisms: 1) oscillatory forcing by ENSO-related wind stress and 2) temporally stochastic and spatially coherent wind stress forcing. Previous studies have shown that transmission of energy from the tropical Pacific to the southern Indian Ocean occurs through coastal Kelvin waves along the western coast of Australia. The results in this paper confirm the occurrence of such transmission. In the ECHO-G simulations, this transmission occurs both at the annual time scale and at interannual time scales. Generation of offshore Rossby waves by these coastal Kelvin waves at interannual time scales-and, in particular, at the ENSO time scale-was found.
\end{abstract}

\section{Introduction}

Several observational, modeling, and theoretical studies have shown that the large-scale variability of the thermocline is dominated by its low-frequency component and that the wind-driven circulation plays an important role in producing this variability. Sturges and Hong (1995) analyzed the Bermuda tide gauge record and showed that sea level variability at decadal time scales is consistent with an oceanic response, in the form of baroclinic Rossby waves, to wind stress forcing across the Atlantic Ocean. Experiments with coupled general circulation models (CGCM) also suggest that the decadal variability of the midlatitude thermocline in the North Pacific Ocean is largely wind-driven (e.g., Latif and Barnett 1994). Frankignoul et al. (1997, hereinafter FMZ) suggested by using a simple stochastic model that Atlantic decadal variability primarily reflects the thermocline response to the stochastic atmospheric forcing. Sirven et al. (2002, hereinafter SFCT)

Corresponding author address: Dr. Astrid Baquero-Bernal, Max-Planck Institut für Meteorologie, Bundesstrasse 53, 20146 Hamburg, Germany.

E-mail: baquero@dkrz.de extended the FMZ model and investigated the Rossby wave response to stochastic wind stress forcing in the midlatitudes with emphasis on the impact of horizontal mixing and zonal variations of the forcing.

Studies based on upper-ocean temperatures and satellite altimetric data have detected baroclinic Rossby waves in low latitudes. In the tropical south Indian Ocean (SIO), westward-propagating thermocline depth anomalies have been detected at interannual time scales and attributed to oceanic Rossby waves (Perigaud and Delecluse 1993; Masumoto and Meyers 1998; Chambers et al. 1999; Birol and Morrow 2001).

In a study with oceanic and atmospheric data from reanalysis products, Xie et al. (2002) showed that there is an open-ocean upwelling zone in the tropical western SIO, and that in this upwelling zone there is a strong influence of thermocline movements on sea surface temperature (SST). The thermocline effect on SST in the western tropical SIO is made possible by the presence of both upwelling and a shallow thermocline in this region. Additionally, the authors found that ENSO and processes off Sumatra, Indonesia, are the dominant forcings for the SIO thermocline variability through the forcing of Rossby waves, which propagate westward 
and interact with the atmosphere. The interaction consists of a switch from a positive thermocline feedback to a negative thermocline feedback. Both feedbacks include the propagation of SST and wind stress curl (WSC) anomalies with the positive thermocline depth anomalies produced by the Rossby wave. For the positive (negative) feedback, the WSC anomalies reinforce (dissipate) the thermocline depth anomalies. Thus, through the effect of the SIO Rossby waves on SST, the waves offer potential predictability for SST and tropical cyclones in the western SIO in the boreal winter and spring seasons.

Studies of the large-scale variability of the thermocline forced by stochastic wind stress have been concentrated on decadal to interdecadal variability in the midlatitudes (Frankignoul et al. 1997; Jin 1997; Sura et al. 2000; Sirven et al. 2002). In this paper, the stochastic model by SFCT is used to test if the interannual variability of sea surface height (SSH) related to Rossby waves in the tropical SIO can be explained by the passive response of the ocean to stochastic wind stress forcing - that is, the day-to-day changes in wind stress forcing that are associated with random weather fluctuations. The concept of the stochastic climate model was first proposed by Hasselmann (1976) and is based on the Brownian motion analog. According to this picture, the observed red spectrum of oceanic fluctuations is the response to stochastic atmospheric variability. Stochastic climate models have been widely applied in literature. The stochastic climate model concept has been used for the study of, for example, the decadal variability of the thermohaline circulation, upper-tropospheric dynamics, interannual variability of open-ocean deep convection, and glacial climate variability. The reader is referred to the review paper by Frankignoul (1995) to obtain more details about the stochastic climate model. It is used in the present paper in the form of the SFCT model to study the thermocline variability at interannual time scales due to wind stress forcing.

Our major conclusion is that the SFCT model's spectral predictions of the baroclinic response to temporally white wind stress curl forcing are consistent with the sea level observational data at Cocos Island $\left(12^{\circ} \mathrm{S}, 96.5^{\circ} \mathrm{E}\right)$ and with an experiment using a CGCM in which ENSO was suppressed. In particular, the shape and power level of the frequency spectra of model SSH at various longitudes at $10^{\circ} \mathrm{S}$ are well predicted by the SFCT model. Furthermore, the predictions for sea level at Cocos Island correspond well to the observations. This suggests that a stochastic climate model is an appropriate starting point for understanding interannual changes in the tropical SIO that are independent of the interannual variability in the Pacific.

The paper is arranged as follows: Section 2 introduces the model datasets used. Section 3 presents the statistical analysis of the space-time structure of $\mathrm{HC}$ anomalies in the tropical Indian Ocean based on the method of principal oscillation patterns. Section 4 introduces the SFCT stochastic model. Section 5 presents the comparison between the theoretical predictions by the SFCT model and the interannual sea surface height variability in two experiments with the CGCM ECHO-G (Legutke and Voss 1999). Section 6 shows the comparison of the theoretical predictions with sea level observations at Cocos Island. The transmission of energy from the tropical Pacific to the southern Indian Ocean through coastal Kelvin waves along the western coast of Australia is examined in section 7. Conclusions are given in section 8 .

\section{Model data}

The data from two experiments with the coupled ocean-atmosphere general circulation model "ECHOG" are used: in one experiment, sea surface temperatures are set to climatological values in the Pacific region that stretches from $40^{\circ} \mathrm{N}$ to $40^{\circ} \mathrm{S}$ in order to suppress ENSO (non-ENSO experiment). In the other experiment, interactions are allowed everywhere (control experiment). The two experiments were also analyzed by Baquero-Bernal et al. (2002), who examined dipole-like SST variability in the tropical Indian Ocean. The CGCM ECHO-G consists of version 4 of the Hamburg atmosphere general circulation model, ECHAM4 (Roeckner et al. 1996), and the global version of the Hamburg Ocean Primitive Equation general circulation model, HOPE-G (Wolff et al. 1997), which is a primitive equation $z$-level ocean model, and incorporates a dynamic-thermodynamic sea-ice model with snow cover. The component models are coupled by use of the OASIS coupling software developed at CERFACS (Terray et al. 1998). The ECHO-G model is described in detail in Legutke and Voss (1999). For the ECHO-G simulations presented in this study, ECHAM4 employs a 19-level hybrid sigma-pressure vertical coordinate system, and a horizontal resolution of T30, which corresponds approximately to a horizontal gridpoint distance of $3.75^{\circ}$. HOPE-G employs a zonal resolution of $2.8^{\circ}$ in the whole domain. The meridional resolution is $2.8^{\circ}$ in the extratropics, and it is gradually increased until it reaches $0.5^{\circ}$ within $10^{\circ}$ of the equator. The increased resolution in low latitudes is intended for a better representation of equatorial dynamics. The vertical resolution is 20 levels. The atmosphere component model passes heat, freshwater and momentum fluxes to the ocean and receives surface conditions. These conditions are SST, sea-ice concentration, sea-ice thickness, and snow depth. Annual mean heat and freshwater fluxes, as diagnosed from a 155-yr coupled spinup integration, are used as flux corrections. However, no momentum flux corrections are used.

The monthly anomalies of model heat content (HC), wind stress curl (WSC) and sea surface height (SSH) for $100 \mathrm{yr}$ are considered in the following analysis. For 
each variable, the monthly mean climatology is first calculated. Then, interannual anomalies are computed as the difference from this climatology. Additionally, the local linear trend was subtracted at each point. Heat content has been computed by integration of ocean temperatures from the surface to 206-m depth. The spectra of both model data and observations are calculated using a Bartlett procedure with a Bartlett lag window.

\section{Rossby waves}

The statistical investigation of the space-time structure of $\mathrm{HC}$ anomalies in the tropical Indian Ocean is based on the method of principal oscillation patterns (POPs; Hasselmann 1988; von Storch et al. 1988; Schnur et al. 1993). In the POP analysis, the time evolution of the system is assumed to be generated by a first-order multivariate autoregressive process:

$$
\mathbf{x}(t+1)=\mathbf{A} \mathbf{x}(t)+\text { noise }
$$

Assuming that the noise in Eq. (1) is uncorrelated with $\mathbf{x}(t)$, the matrix $\mathbf{A}$ is estimated from the data by calculating the sample lag- 1 covariance matrix $\mathbf{X}_{1}$ and the sample lag-0 covariance matrix $\mathbf{X}_{0}$, and then forming $\mathbf{A}$ $=\mathbf{X}_{0} \mathbf{X}_{1}^{-1}$. In general, the matrix $\mathbf{A}$ is not symmetric, and thus its eigenvectors $\mathbf{P}$ and eigenvalues $\lambda$ are complex. The complex eigenvalues define a rotation period and an $e$-folding time for exponential decay. The eigenvectors of $\mathbf{A}$, or the normal modes of Eq. (1), are called principal oscillation patterns. In most cases, all eigenvalues are different and the eigenvectors form a linear basis. So, the state $\mathbf{x}(t)$ at any time $t$ may be uniquely expressed in terms of the eigenvectors as:

$$
\begin{gathered}
\mathbf{x}(t)=\sum_{j} z_{j}(t) \mathbf{P}_{j}+\sum_{j}\left[z_{j}^{R}(t) p_{j}^{R}+z_{j}^{I}(t) p_{j}^{I}\right]+\text { noise, } \\
\text { all real POPs } \\
\text { all complex POPs }
\end{gathered}
$$

where $z^{R}$ and $z^{I}$ are the complex coefficient time series.

Since there are as many eigenvalues as grid points in the data, it may be hard to extract the dominant modes. To reduce the space dimension of $\mathbf{x}(t)$ the data may be subjected to an empirical orthogonal function (EOF) expansion prior to the POP analysis. In the present paper such expansion is performed and the first 10 EOFs are retained.

The complex coefficient time series $\left(z^{R}, z^{I}\right)$ describe the time evolution of the POPs and satisfy the standard damped harmonic oscillator equation, so that the evolution of the system in the two-dimensional POP space can be interpreted as a cyclic sequence of spatial patterns:

$$
\ldots-p^{R} \rightarrow p^{I} \rightarrow p^{R} \rightarrow-p^{I} \rightarrow-p^{R} \ldots
$$

The procedure to determine whether a particular POP pair contains useful information includes the following steps (Gallagher et al. 1991): checking whether the POP pair explains relative large variance in the original data, checking whether its corresponding ratio of the $e$-folding time to the oscillation period is greater than $1 / 4$, checking if the variance of its complex coefficient time series $z^{R}$ and $z^{I}$ are of about equal magnitude, and checking in a cross spectral analysis of $z^{R}$ and $z^{I}$ whether they have maximum variance near the POP frequency, whether the phase is close to $-90^{\circ}$ near the POP frequency, and whether the coherence is high. In the present paper, only the POPs pairs that satisfy the above criteria are mentioned. As will be discussed in the following, significant POP modes emerge at both intraseasonal and interannual time scales. Since we are interested in the interannual time scales, only the interannual POP modes are discussed in detail.

For the control experiment, the POP analysis reveals two dominant interannual POP pairs, pop1 and pop2 (Fig. 1). The pop1 pair $\left(p_{1}^{I}, p_{1}^{R}\right)$ accounts for $12 \%$ of the total variance and has a rotation period of 17 months and an $e$-folding time of 9 months. The pop 2 pair $\left(p_{2}^{I}\right.$, $p_{2}^{R}$ ) has a period of 30 months and an $e$-folding time of 11 months, explains $16 \%$ of the total variance and is clearly associated with the ENSO phenomenon. This can be inferred from the correlation of the two time series $z_{2}^{R}$ and $z_{2}^{I}$ with the Niño-3 index: 0.63 when Niño-3 lags $z_{2}^{I}$ by 2 months and 0.63 when Niño-3 leads $z_{2}^{R}$ by 3 months. The local explained variance by each of the two POP pairs for the control experiment is shown in Figs. 2a and $2 b$.

The POP analysis of the $\mathrm{HC}$ anomalies in the nonENSO experiment produces only one dominant interannual POP pair (pop1' pair: $p_{1}^{I^{\prime}}, p_{1}^{R^{\prime}}$; Fig. 3), which bears resemblance to the pop1 pair in the control experiment south of $5^{\circ} \mathrm{S}$. This POP pair has a rotation period of 16 months and an $e$-folding time of 9 months and accounts for $6 \%$ of the total variance. The local explained variance by this POP pair is shown in Fig. 4.

For both the control and non-ENSO experiments, the POP analysis reveals one intraseasonal POP pair (not shown). This POP pair accounts for 5\% (19\%) of the total variance and has a rotation period of 8 (5) months in the control (non-ENSO) experiment. The spatial patterns of this POP pair are consistent with equatorial wave dynamics within $5^{\circ}$ of the equator (i.e., consistent with eastward-propagating Kelvin waves and westward-propagating Rossby waves). A detailed discussion of this intraseasonal POP pair is beyond the scope of this paper.

The cross-spectral analyses of $z^{R}$ and $z^{I}$ corresponding to each of the POP pairs pop1, pop2, and pop1' (not shown), show that the variance of $z^{R}$ and $z^{I}$ is of about the same and has a maximum around the POP frequency. Furthermore, for each POP, $z^{R}$ and $z^{I}$ have a phase shift of $-90^{\circ}$ and the coherence is also well above the $99 \%$ coherence squared level, as expected theoretically.

The overall patterns of the interannual POP pairs in the two experiments are reminiscent of a westwardpropagating signal. This propagation has been studied 
a) pop1 imaginary part $\left(p_{1}^{I}\right)$

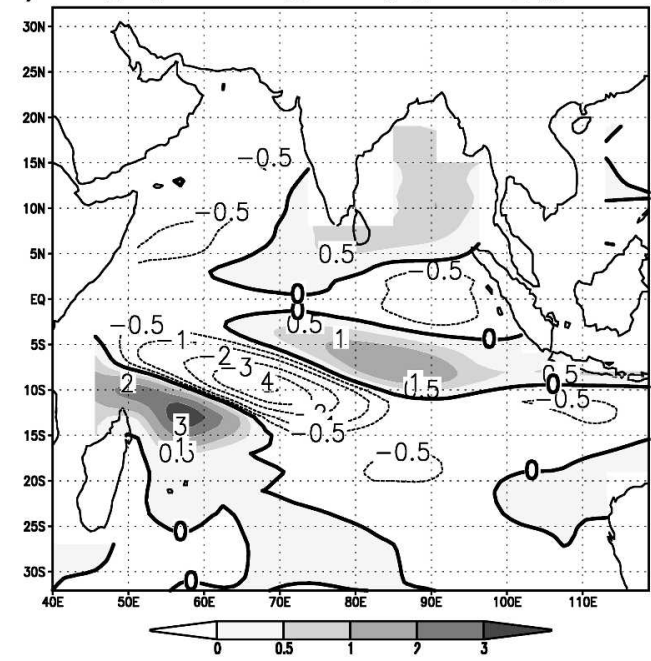

b) pop2 imaginary part $\left(p_{1}^{I}\right)$

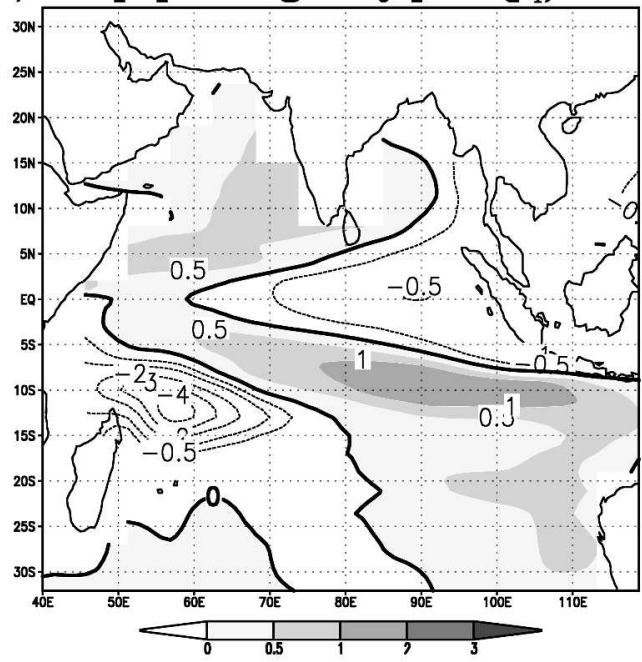

pop1 real part $\left(p_{1}^{R}\right)$
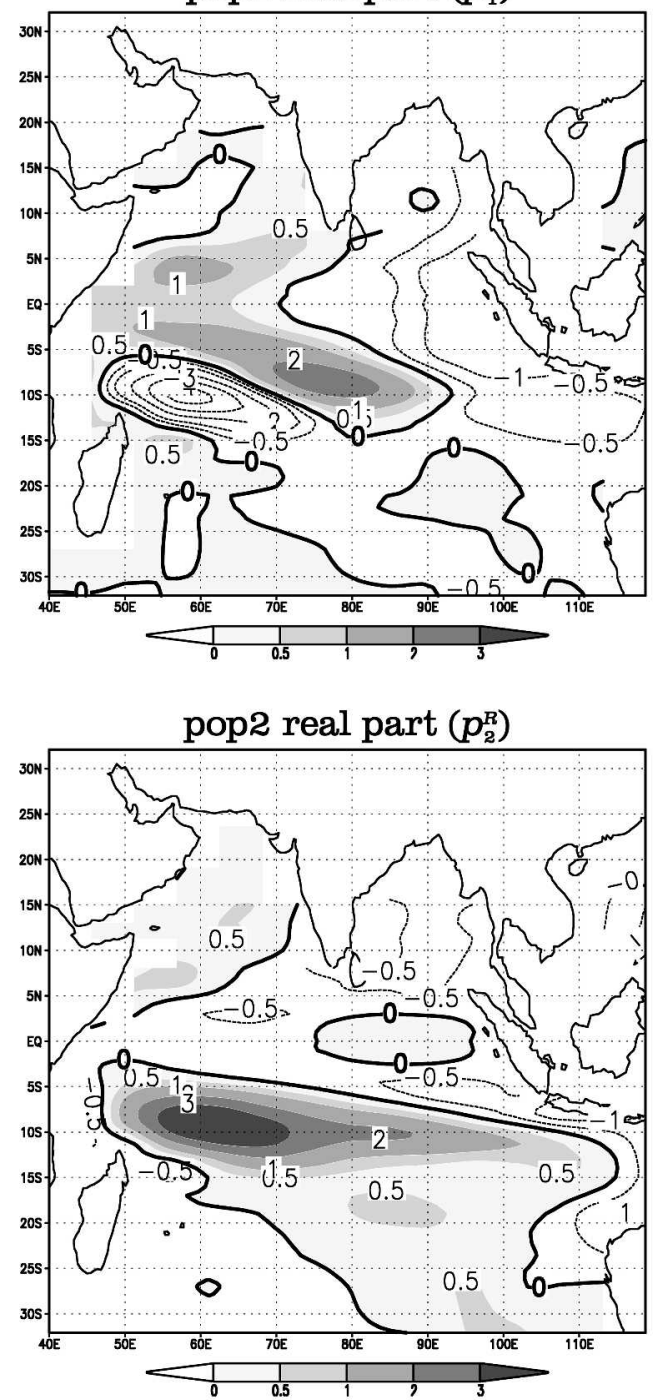

c)

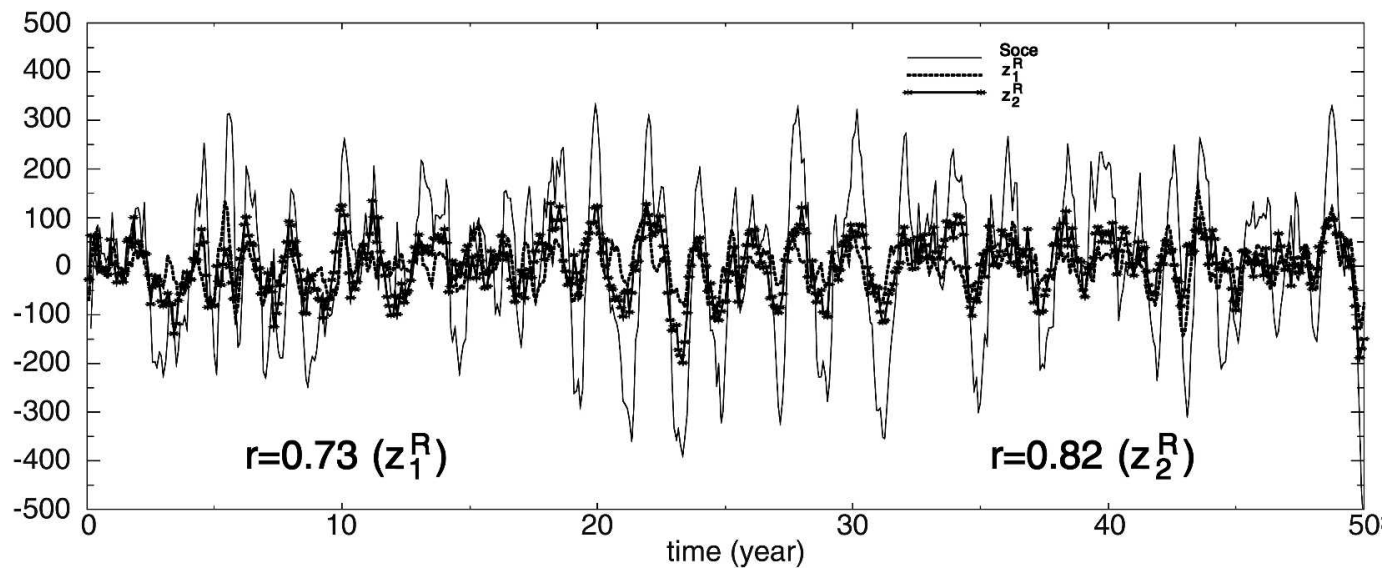

FIG. 1. Dominant POPs of HC anomalies simulated in the control experiment: (a) pop1, (b) pop2, and (c) Soce index along with $z^{R}$ time series (only the first $50 \mathrm{yr}$ of the time series are shown; correlations between Soce index and $z_{1}^{R}$ and $z_{2}^{R}$ are shown in the lower part). Pop1 has a period of 17 months and explained variance of $12 \%$. Pop2 has a period of 30 months and explained variance of $16 \%$. The correlation between $z_{1}^{R}$ and $z_{2}^{R}$ is 0.6 . Shaded areas denote positive values. In (a) and (b), the imaginary part is on the left and the real part on the right. 
a) Local variance explained by pop1

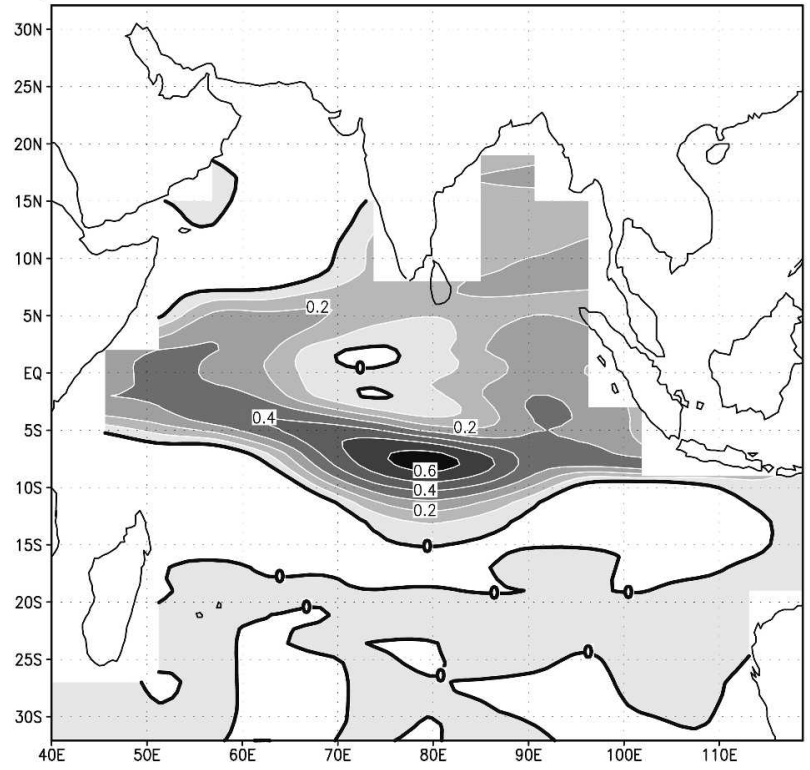

b) Local variance explained by pop2

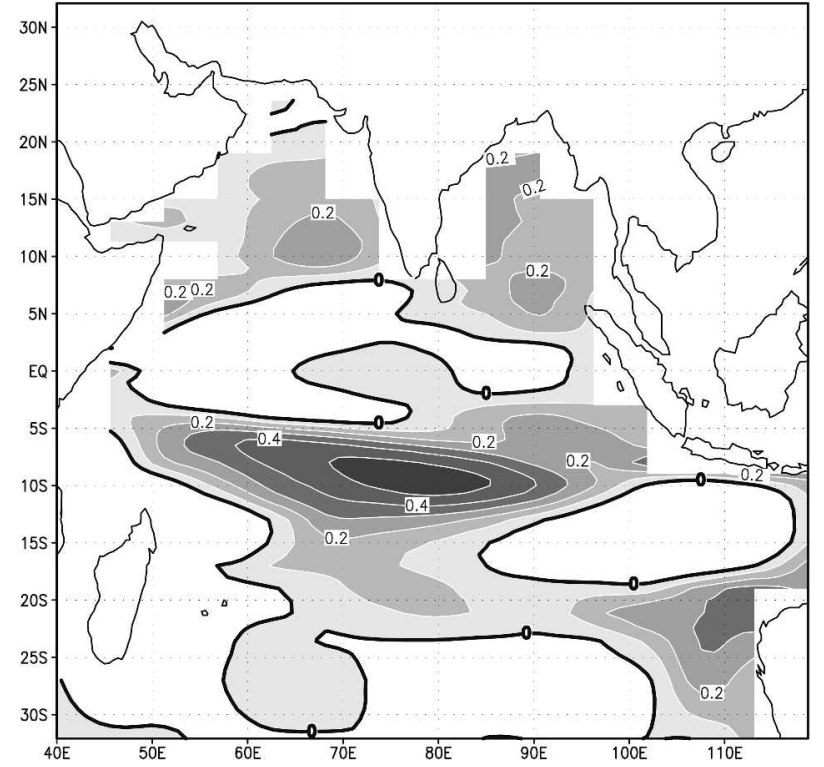

FIG. 2. Local variance explained by the POP pairs for the control experiment shown in Fig. 1. (a) Local variance explained by pop1 and (b) local variance explained by pop2. Only positive values are shown. Contour interval is 0.1 .

using observations and ocean models and identified as Rossby waves (Perigaud and Delecluse 1993; Masumoto and Meyers 1998). The $p_{1}^{I}\left(p_{2}^{I}\right)$ pattern of pop1 (pop2) is followed after 4 (7) months by the $p_{1}^{R}\left(p_{2}^{R}\right)$ pattern. The $p_{1}^{I}\left(p_{2}^{I}\right)$ pattern exhibits positive HC anomalies between $5^{\circ}$ and $15^{\circ} \mathrm{S}$ that are located in the middle (eastern) part of the basin. A band of negative $\mathrm{HC}$ anomalies is found at the eastern equatorial zone. The positive anomalies of the $p_{1}^{I}\left(p_{2}^{I}\right)$ pattern have moved westward in the $p_{1}^{R}\left(p_{2}^{R}\right)$ pattern. Negative anomalies are found at the eastern part of the basin on (off) the equator in the $p_{1}^{R}\left(p_{2}^{R}\right)$ pattern. The pop1' pair structure in the non-ENSO experiment resembles pop1 of the control experiment and is also reminiscent of a Rossby wave packet south of the equator. The main difference between these two pairs is that pop1' of the non-ENSO experiment does not have significant $\mathrm{HC}$ anomalies at and north of the equator.

To track the variability associated with Rossby waves in the two experiments an index is constructed from the monthly $\mathrm{HC}$ anomalies averaged over $8^{\circ}-12^{\circ} \mathrm{S}, 75^{\circ}-$ $85^{\circ} \mathrm{E}$. This index is referred to as south central index (Soce). The Soce region was selected, since the $z^{R}$ time series of the interannual POP pairs are highly correlated with the $\mathrm{HC}$ anomalies in the region. The correlations of Soce index with the $z^{R}$ time series of the dominant POPs in the two experiments are as follow: 0.7 with $z_{1}^{R^{\prime}}, 0.7$ with $z_{1}^{R}$ and 0.8 with $z_{2}^{R}$. The pop1' explains $35 \%$ of the variance in the Soce region, the pop 1 explains $30 \%$ and the pop 2 explains $47 \%$. The location of the Soce index deduced from the two experiments coincides with the location of a thermocline depth index proposed in Xie et al. (2002). Their index was used to illustrate the time-space evolution of thermocline variability in the SIO in the Simple Ocean Data Assimilation (SODA) product (Carton et al. 2000). The coincidence in the location of the indices gives confidence in the performance of the ECHO-G model. The POP pairs have been rotated in such a way that $z^{R}$ has a maximum correlation with the Soce index.

The Rossby waves can be seen as the tendency for westward propagation of HC anomalies. The zonal sections of $\mathrm{HC}$ anomalies along $10^{\circ} \mathrm{S}$ for years $24-33$ in both experiments are compared in Fig. 5. As an example of such westward propagation, one wave is followed in each experiment (Figs. 5a,b): for the control experiment (non-ENSO experiment) there is a downwelling wave in years 27-28 (26-27) that has positive anomalies at $95^{\circ} \mathrm{E}\left(90^{\circ} \mathrm{E}\right)$ in May of year 27 (July of year 26), it then travels to the west and can be traced to $50^{\circ} \mathrm{E}$ in July of year 28 (September of year 27). These waves have an estimated westward speed of about 14 $\mathrm{cm} \mathrm{s}^{-1}$ for both experiments, which is in agreement with the estimates of Xie et al. (2002). Reconstruction of the $\mathrm{HC}$ anomalies were computed by using the POP modes from the two experiments shown in Figs. 1 and 3. The Rossby wave propagation is seen first in the two pop1 modes (Figs. 5c,d), while the reconstruction using the ENSO-related pop2 mode of the control integration exhibits a stronger standing component (Fig. 5e).

\section{The stochastic model}

Since SFCT's 1997 stochastic model is essential in the present study, a brief description is presented in the 
(a)
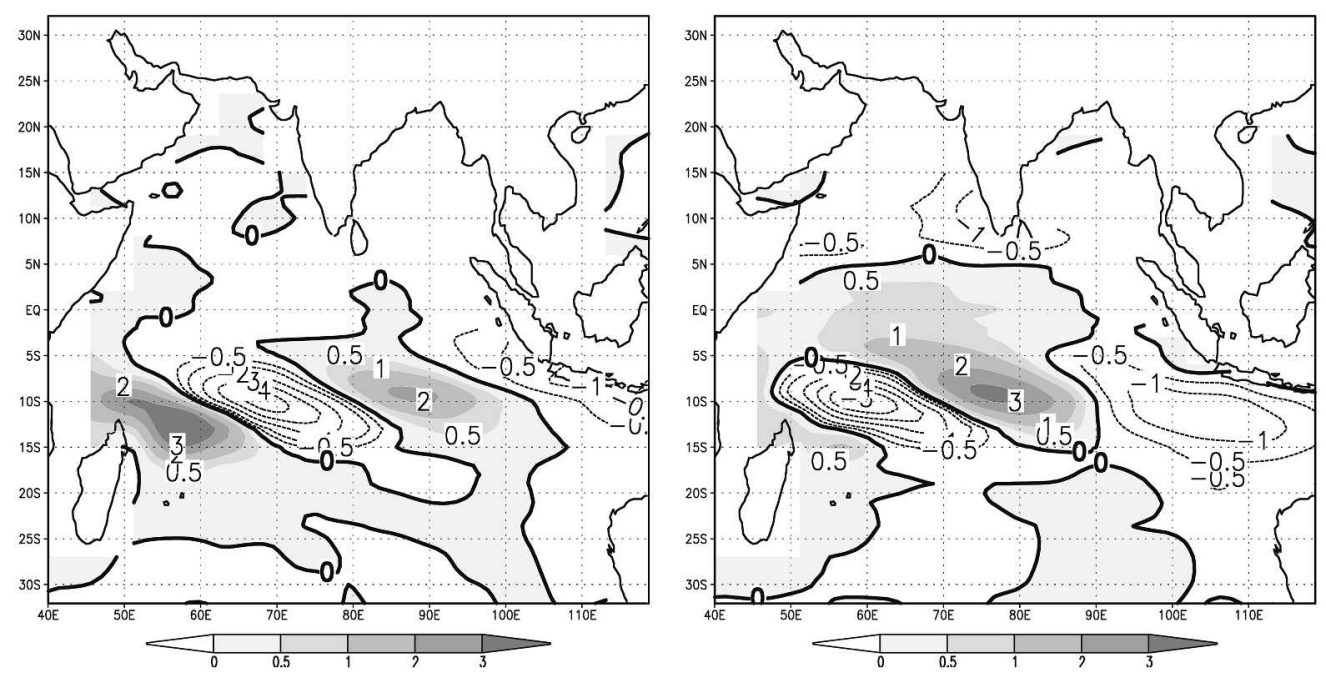

(b)

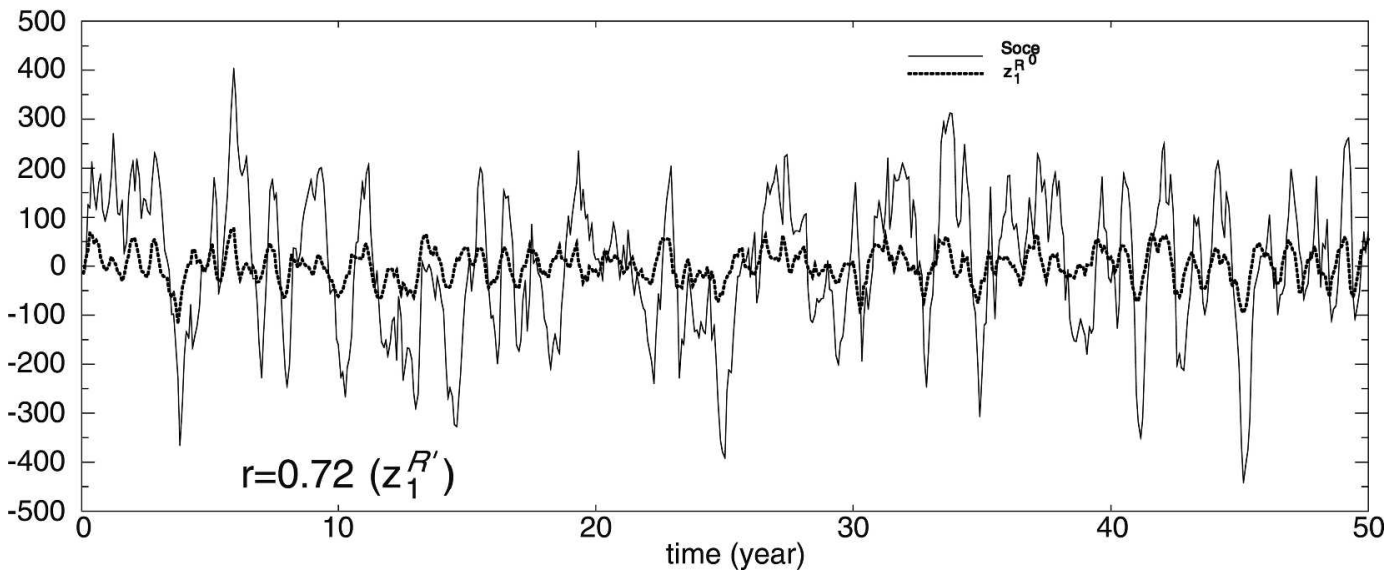

FIG. 3. Dominant POP of HC anomalies simulated in the non-ENSO experiment: (a) pop1' and (b) Soce index along with $z_{1}^{R^{\prime}}$ time series (only the first $50 \mathrm{yr}$ of the time series are shown; correlation between Soce index and $z_{1}^{R^{\prime}}$ is shown in the lower part). Pop1' has a period of 16 months and explained variance of $6 \%$. Shaded areas denote positive values.

following. The model consists of a time-dependent geostrophic 2.5-layer ideal-fluid model of the ventilated thermocline. The effect of the mean flow is taken into account. At the eastern boundary a no-normal flow condition is imposed and at the western boundary a no-radiation condition. The only forcing is the surface wind stress transmitted to the ocean by Ekman pumping. Western boundary dynamics are excluded; therefore the model only applies east of the western boundary current region. A downward Ekman pumping $w_{e}$ is imposed at the surface of a subtropical gyre limited to vanish at $y=y_{N}$ and $y=y_{S}$. The lightest layer of density $\rho_{1}$ and thickness $h_{1}$ is located south of the latitude $y_{1}\left(y_{S}<y_{1}<y_{N}\right)$, where the second layer of density $\rho_{2}$ and thickness $h_{2}$ outcrops. The depth $H=h_{1}$ $+h_{2}$ represents the base of the thermocline. The abyss is a third layer at rest, with a density $\rho_{3}$ and an infinite depth. The last characteristic is consistent with the rigid lid condition imposed at the surface. The $\beta$ plane approximation, which assumes that the Coriolis parameter varies linearly with latitude, is used. The zonal coordinate is denoted by $x$ and the eastern and western boundaries are at $x=0$ and $x=x_{w}<0$. For the present study, the eastern boundary is located at $110^{\circ} \mathrm{E}$. The geostrophic zonal flow vanishes at the eastern boundary $\left(h_{1}=0\right.$ and $H=h_{2}=H_{0}=200 \mathrm{~m}$ at $\left.x=0\right)$, while a no-radiation condition is used at the western boundary. The effective depth is given by

$$
\mathcal{H}=\sqrt{\frac{\gamma_{1}}{\gamma_{2}} h_{1}^{2}+H^{2}},
$$




\section{Local variance explained by pop1'}

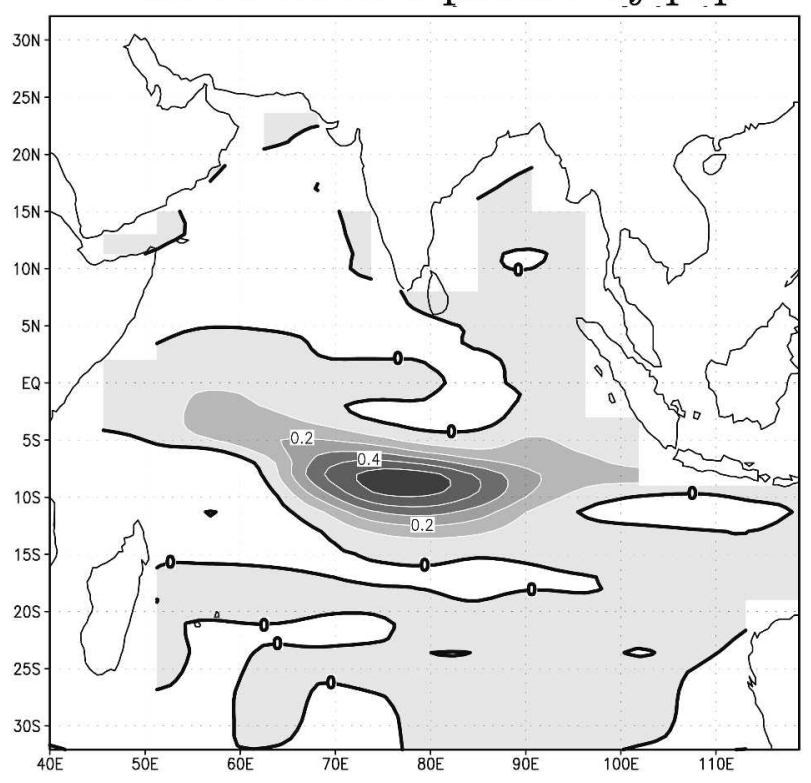

FIG. 4. Local variance explained by pop1' for the non-ENSO experiment shown in Fig. 2. Only positive values are shown. Contour interval is 0.1 .

where $\gamma_{1}=\left(\rho_{2}-\rho_{1}\right) g / \rho_{0}$ and $\gamma_{2}=\left(\rho_{3}-\rho_{2}\right) g / \rho_{0}$ represent the reduced gravities associated with each layer and both are much smaller than gravity $g ; \rho_{0}$ is a reference density. The variable $\mathcal{H}$ characterizes the overall response of the thermocline to a variation in $w_{e}$, including the effect of the mean flow. The evolution equation for the effective depth $\mathcal{H}$ is given by

$$
\frac{\partial \mathcal{H}}{\partial t}-c_{1} \frac{\partial \mathcal{H}}{\partial x}=\lambda w_{e}
$$

where $\lambda$ is a constant $(\simeq 1), c_{1}=\beta \gamma_{2} \lambda \mathcal{H} / f^{2}$, and $f$ is the Coriolis parameter.

In particular, the linearized version of Eq. (4) with dissipation in the long-wave approximation is used, which takes into account the influence of horizontal mixing and describes the free waves of the first baroclinic mode as

$$
\frac{\partial \mathcal{H}^{\prime}}{\partial t}-c_{b} \frac{\partial \mathcal{H}^{\prime}}{\partial x}=-\frac{c_{b}}{x_{e}} \mathcal{H}^{\prime}+\text { wind stress forcing, }
$$

where $\mathcal{H}^{\prime \prime}$ represents the fluctuations of the equivalent depth around its mean and characterizes the overall response of the thermocline to a variation in the wind forcing, $x$ is the zonal coordinate that measures the distance from the eastern boundary, $c_{b}$ is the mean value of the Rossby wave phase speed at a given latitude, and $x_{e}$ defines an $e$-folding distance from the eastern boundary that represents the influence of horizontal mixing (Qiu et al. 1997). This $e$-folding distance is given by $x_{e} \approx\left(5 c_{b}^{4} f^{4} / 16 \omega^{4} A_{h} \beta^{3}\right)$, where $w$ is the frequency and $A_{h}$ is the horizontal eddy viscosity. The $x_{e}$ distance becomes infinite at low frequency and it van- ishes at high frequency (SFCT), since it is defined through a bi-Laplacian dissipation.

Latitude enters Eq. (5) only as a parameter. Thus, the response can be calculated for every latitude separately with the appropriate values of $f, \beta, c_{b}$, and $A_{h}$ and by providing a functional form for the wind stress forcing term that gives the temporal and spatial dependence of the forcing. In the following, two general cases will be considered: zonally independent forcing (section 4a) and zonally dependent forcing (section 4b).

\section{a. Zonally independent forcing}

The wind stress forcing associated with the day-today weather fluctuations can be represented in Eq. (5) by the Ekman pumping fluctuations $\hat{F}(x, f, \omega)=\hat{F}(\omega)$ $\exp (i \omega t)$. As a first-order approximation, it is assumed that $\hat{F}$ is independent of the zonal coordinate $x$.

Additionally, the spectrum of the Ekman pumping forcing $S_{F}$ is assumed to be temporally white: $S_{F}(\omega)=$ $S_{0}$, where $S_{0}$ is a constant. Under these two conditions for the wind stress forcing the response spectrum $S_{R}$ is given by

$$
\begin{aligned}
S_{R}(\omega, x)= & \frac{S_{0}}{\omega^{2}+\omega_{d}^{2}} \\
& \times\left[\left(1-e^{x / x_{e}}\right)^{2}+4 e^{x / x_{e}} \sin ^{2}\left(\frac{\omega x}{2 \omega_{d} x_{e}}\right)\right],
\end{aligned}
$$

where $\omega_{d}=c_{b} / x_{e}$.

Equation (6) resembles the response spectrum obtained by FMZ, although they did not take into account dissipation by zonal mixing as done in SFCT. A noteworthy fact is that the response is $x$-dependent even though the forcing is not.

At lower frequencies, the response spectrum flattens toward a constant level $S_{0}$ :

$$
S_{R}(\omega \rightarrow 0, x)=S_{0}\left(x / c_{b}\right)^{2},
$$

which increases quadratically with the distance from the eastern boundary. FMZ identified the baroclinic response as a red spectrum with a dominant period determined by the time for a long nondispersive baroclinic Rossby wave to cross the entire basin. This period increases with the basin width. The spectral decay at high frequencies [higher than $(10 \text { month })^{-1}$ ] is somewhat faster than $w^{-2}$ because of the exponential term in Eq. (6), except for $x / x_{e} \ll-1$ when dissipation becomes dominant, in this case $S(x, w)=S_{0} / w^{2}$ (SFCT).

\section{b. Zonally dependent forcing}

In this case, the Ekman pumping forcing is represented by a superposition of harmonic components $\hat{F}(k$, $\omega) \exp [i(\omega t+k x)]$ and its corresponding wavenumberfrequency spectrum by $S_{F}(k, w)=S_{F}(k, 0)=S_{e}(k) S_{0}$, that now depends on the zonal wavenumber $k$ but is still assumed to be temporally white. The response 

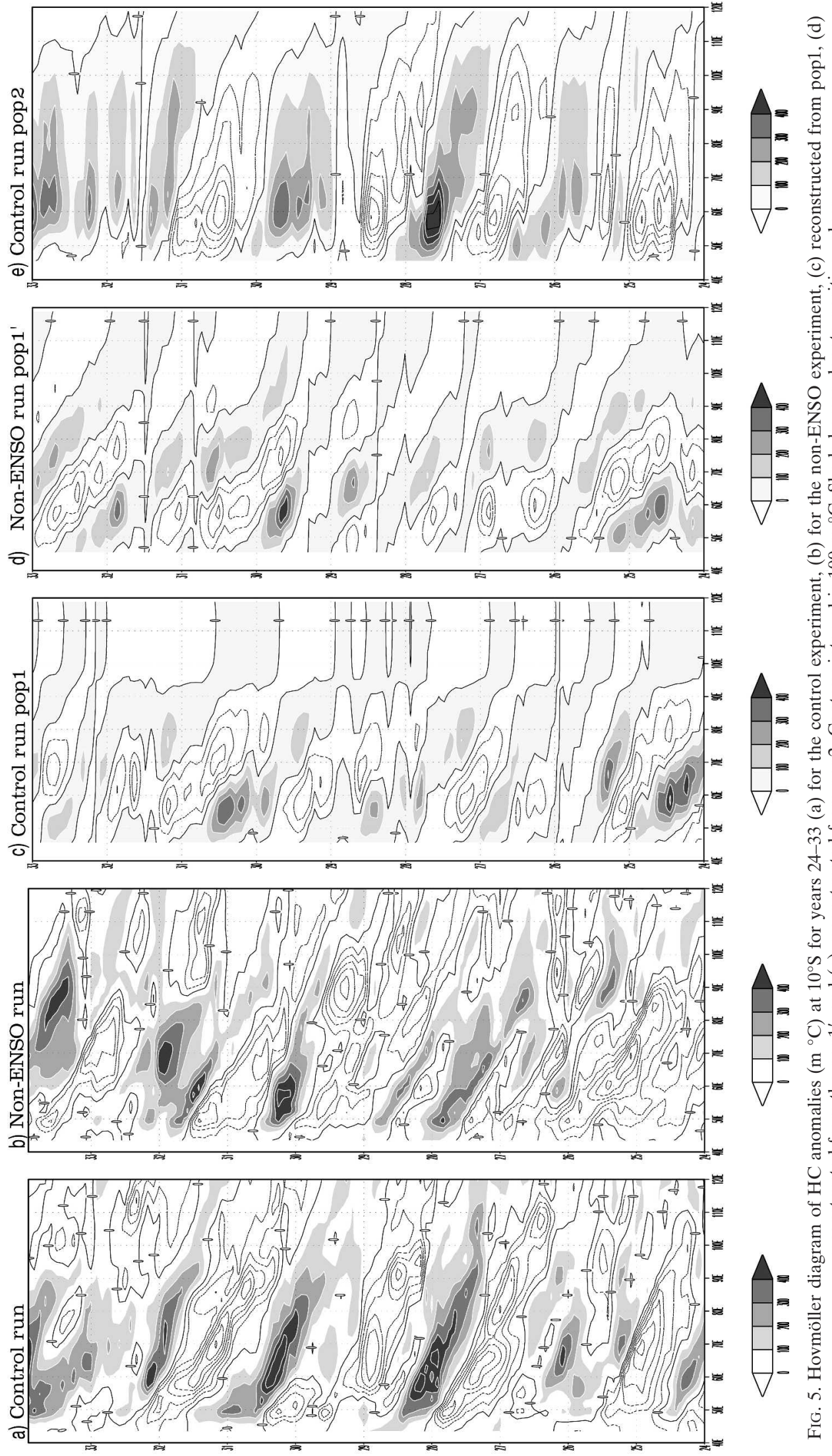


\section{a) Control experiment}

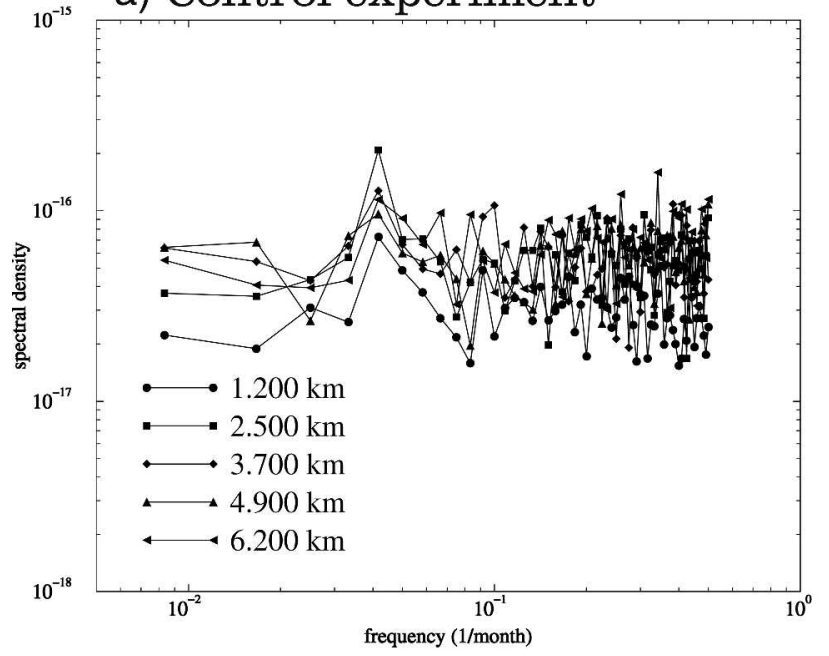

b) Non-ENSO experiment

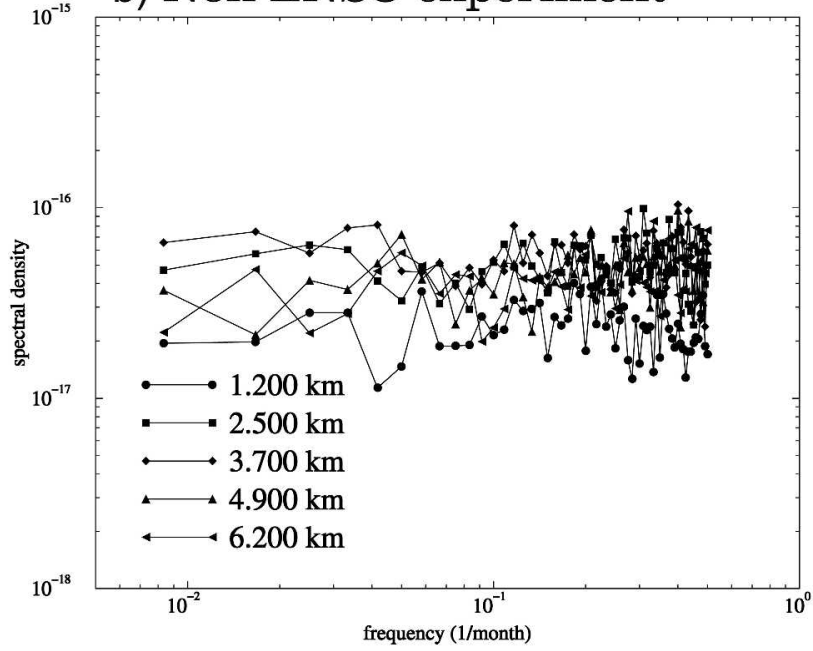

FIG. 6. Frequency spectrum of surface wind stress curl at $10^{\circ} \mathrm{S}$ at various distances from the eastern boundary, which is located at $110^{\circ} \mathrm{E}$, (a) for the control experiment and (b) for the non-ENSO experiment.

spectrum $S_{R}$ under the above conditions for the wind forcing is

$$
\begin{aligned}
S_{R}(k, x, \omega)= & \frac{S_{e}(k) S_{0}}{\left(\omega-k c_{b}\right)^{2}+\omega_{d}^{2}} \\
& \times\left[\left(1-e^{x / x_{e}}\right)^{2}+4 e^{x / x_{e}} \sin ^{2} \frac{\left(\omega-k c_{b}\right) x}{2 c_{b}}\right] .
\end{aligned}
$$

Equation (8) indicates that there is a peak at the resonance frequency $\omega_{r}=k_{0} c_{b}$ of a free Rossby wave of wavenumber $k_{0}$. The speed of the Rossby waves along $10^{\circ} \mathrm{S}$ in the Indian Ocean is $c_{b}=14 \mathrm{~cm} \mathrm{~s}^{-1}$. The dominant synoptic spatial scale of atmospheric variability has a wavelength of between 4000 and $5000 \mathrm{~km}$ (Holton 1992). For these values of $c_{b}$ and wavelength the period is about 12 months. When Eq. (8) is integrated over a reduced finite number of wavenumbers around $k_{0}$, it may be possible to obtain a frequency spectrum that still has a small peak at frequency $\omega_{r}=k_{0} c_{b}$. However, this resonance in a bounded ocean basin is only capable of producing a weak spectral peak in the response spectrum because of the fact that the basin boundary implicitly poses a damping effect to limit the resonance, which otherwise is unlimited for undamped Rossby waves in a globally periodic ocean. Furthermore, the weak resonant peak can be further flattened when ocean dynamic damping is acting. Thus, this weak frequency peak is potentially not sufficient to account for observed variability at the time scale related to it (Jin 1997).

If the wind stress can be considered as a continuum of zonal scales between $-k_{M}$ and $k_{M}$, the frequency spectrum can be computed by integrating Eq. (8) be- tween these two wave numbers if an expression for $S_{e}(k)$ is provided.

Different expressions for $S_{e}(k)$ can be considered. SFCT examined two kinds of spatial dependence: $S_{e}(k)$ is constant for a finite interval of $k \mathrm{~s}$ or a $k^{-2}$ dependence is assumed. Only the first case is reviewed here.

The first case consists of a wind stress curl spectrum with $S_{e}(k)$ being constant between $-k_{M}$ and $k_{M}$ and equal to zero outside this range:

$$
\begin{aligned}
S_{F}(k) & =S_{0} S_{e}(k) \\
& = \begin{cases}\frac{S_{0}}{2 k_{M}} & \text { for } k \text { between }-k_{M} \text { and } k_{M} \\
0 & \text { otherwise. }\end{cases}
\end{aligned}
$$

At very low frequencies and for large zonal distances $x$ (larger than $3000 \mathrm{~km}$ ), the response spectrum is

$$
S_{R}(x, \omega) \approx \frac{\pi S_{0}|x|}{k_{M} c_{b}^{2}} .
$$

This implies that if the wind stress curl is constant for a finite interval of $k \mathrm{~s}$ and temporally white, the response frequency spectrum is white at low frequency, and its level increases linearly with distance from the eastern boundary.

\section{Comparison with a CGCM}

\section{a. Wind stress curl spectra}

The frequency spectra of the WSC anomalies along $10^{\circ} \mathrm{S}$ at various distances in the Indian Ocean are shown for the two experiments in Fig. 6. The distances are measured with respect to the eastern boundary, which is located at longitude $110^{\circ} \mathrm{E}$. The frequency spectra in 
the control experiment (Fig. 6a) have a peak of enhanced variability at the frequency of $(25 \text { month })^{-1}$, which corresponds well to the ENSO period in the ECHO-G model. This peak at interannual time scales in WSC is consistent with the idea of an oscillatory forcing of Rossby waves in the SIO due to Ekman pumping changes induced by ENSO. On the other hand, the frequency spectra in the non-ENSO experiment are essentially white (Fig. 6b). The white noise level tends to be a bit larger in the center of the basin, but the zonal changes are small. Thus, the forcing in the non-ENSO experiment can be considered as temporally white, such as it is assumed in the stochastic forcing theory shown in section 4 . Therefore, focus is set on the non-ENSO experiment in the following. The propagating components (eastward, westward) of the zonal wavenumber spectrum of the WSC anomalies at $10^{\circ} \mathrm{S}$ in the non-ENSO experiment are shown in Fig. 7. The power is mainly concentrated at large scales, decaying as $k^{-3}$ for wavelengths longer than $5500 \mathrm{~km}$ and as $k^{-4}$ for shorter wavelengths. Since such a $S_{e}(k)$-dependence on $k$ has not been examined before, it is necessary to derive an expression for this case. The following $S_{e}(k)$ dependence is proposed:

$$
S_{F}=S_{0} S_{e}(k)=\frac{3 \sqrt{3}}{4 \pi} S_{0} \frac{k_{M}^{2}}{k_{M}^{3}+|k|^{\beta}} .
$$

Forcing $S_{F}$ now depends on $k$ as $|k|^{-3}$ and is still assumed to be temporally white. It is also symmetric, so that there is no privileged zonal direction.

The numerical integration of Eq. (8) over $k$ with $S_{F}$ defined as in Eq. (11) leads to a frequency spectrum, whose level increases linearly with the distance from the eastern boundary (not shown), in a similar way as in the case of zonally dependent forcing considered in section $4 \mathrm{~b}$.

\section{b. Comparison with the stochastic model predictions}

In this section and in section 6, a quantitative comparison of the predictions for the response spectrum by the SFCT model against the spectra obtained from the non-ENSO experiment and from observations is performed. Such comparison requires the specification of the adjustable parameters that enter Eq. (8). The values chosen for the theoretical predictions in Figs. $8 \mathrm{~b}$ and 9 are listed in Table 1. With these values, the SFCT model nicely reproduces the spectral level at high and low frequencies simulated in the non-ENSO experiment (Fig. 8). East of $60^{\circ} \mathrm{E}$ (at distances longer than $\approx 6200 \mathrm{~km}$ ), the frequency spectra of the monthly fluctuations of sea surface height (SSH) at $10^{\circ} \mathrm{S}$ in the nonENSO experiment have a shape consistent with the stochastic model predictions. As shown in Figs. 8a and 8b, the power flattens at low frequencies (at periods longer

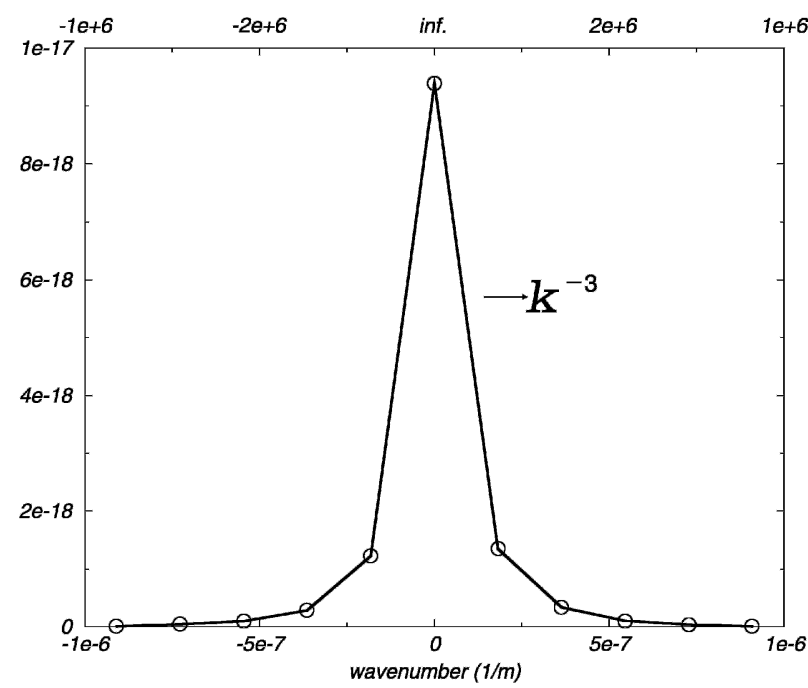

FIG. 7. Wavenumber spectrum of surface wind stress curl at $10^{\circ} \mathrm{S}$ in the non-ENSO experiment $\left(\mathrm{Pa} \mathrm{m}^{-1}\right)$. Note that the upper $x$-axis label indicates wavelength.

than 10 months) at a level that increases with the distance from the eastern boundary. Figures $8 \mathrm{a}$ and $8 \mathrm{~b}$ also show that the power decreases as $\sim w^{-2.6}$ at high frequencies, with a level that does not depend on the distance $x$ to the eastern boundary (i.e., not dependent on the longitude). West of $60^{\circ} \mathrm{E}$, the mean ocean currents are generally stronger than the currents in the open-ocean regions, so that a theory for an ocean with mean zonal flow is less likely to apply.

The $x$ dependence of the oceanic response spectrum at low frequencies is between linear and quadratic. To document more precisely the zonal changes, Fig. 9 shows the SSH-power in four frequency bands centered around 1/180, 1/60, 1/32,1/20 (month $\left.{ }^{-1}\right)$ as a function of longitude. The power dependence on longitude is compared in Fig. 9 with a parabola [Eq. (7), i.e., spatially and temporally white] and a straight line [Eq. (10), i.e., temporally white and spatially constant for a finite interval of wavenumbers]. The straight line is obtained from a least square fit of all the points on Fig. 9. The typical wavelength of synoptic disturbances in the atmosphere is about $4000 \mathrm{~km}$; then $2 \pi / k_{M}=4000 \mathrm{~km}$. Since $S_{0} / c_{b}^{2}$ should be the same for the straight line and the parabola and the value of $2 \pi / k_{M}$ is known, the parabola can be obtained substituting these values in Eq. (7).

Figure 9 shows that at periods around 20 months the level of the response frequency spectrum increases almost linearly. This illustrates that a better agreement with the non-ENSO experiment data at short periods is obtained when the spatial dependence of the forcing in Eq. (8) is taken into account, that is, when zonally independent forcing is replaced by zonally dependent forcing. A similar improvement is obtained by SFCT in their study about the midlatitude variability in the 
a)

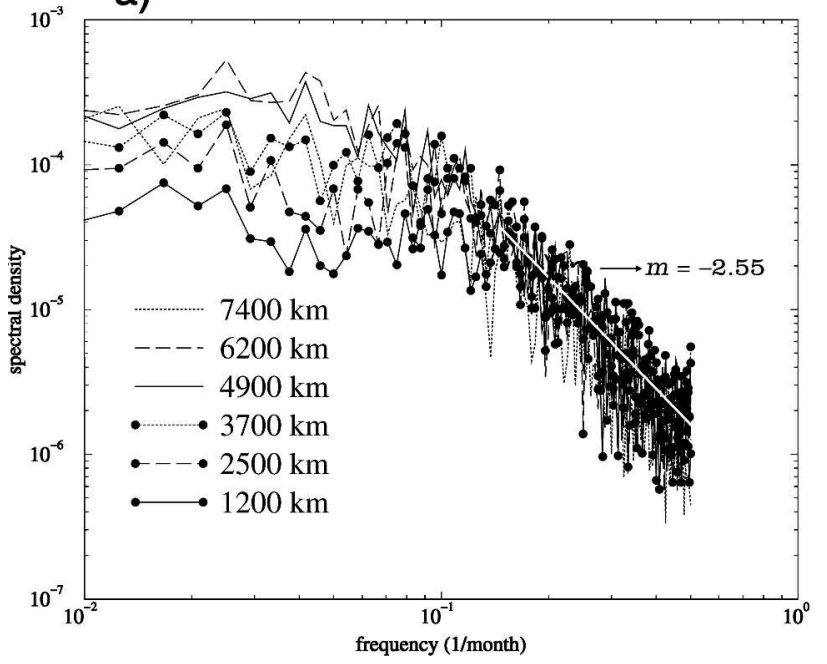

b)

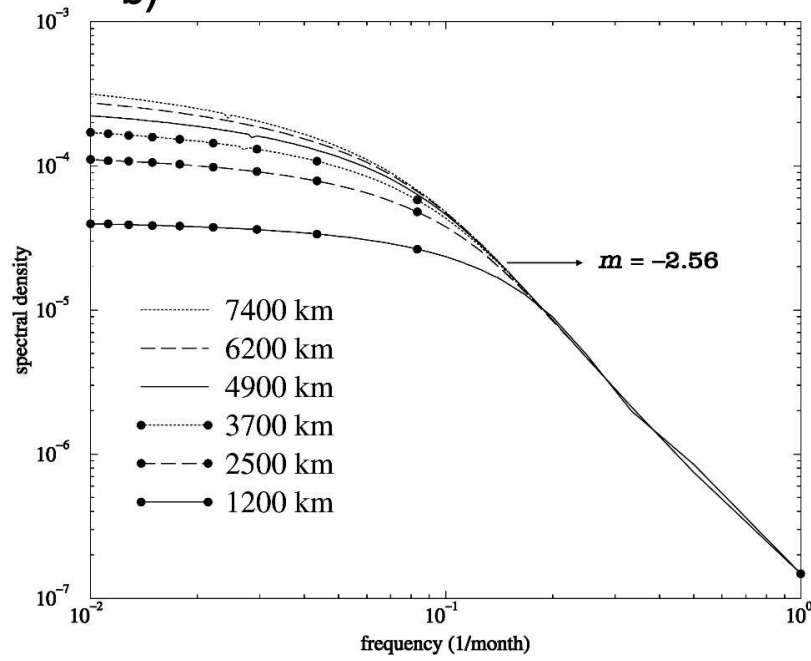

FIG. 8. Frequency spectrum of the sea surface height at $10^{\circ} \mathrm{S}$ at various distances from the eastern boundary, which is located at $110^{\circ} \mathrm{E}$, (a) for the non-ENSO experiment and (b) as predicted by the stochastic model. The white straight line in (a) corresponds to the amplitude average at high frequencies, which was calculated based on the spectra for the distances going from 1200 to $6200 \mathrm{~km}$ and whose slope $m$ is indicated with an arrow. The slope for the predicted spectra in (b) is also indicated.

North Atlantic Ocean. Figure 9 also shows that at lower frequencies the longitude dependence is between linear and quadratic, becoming closer to quadratic at the longest periods.

\section{c. Discussion}

The analyses presented in sections $5 \mathrm{a}$ and $5 \mathrm{~b}$ suggest that a major part of the interannual variability in the tropical SIO sea surface height in the non-ENSO experiment is directly forced by the wind stress curl via Ekman pumping. Since the wind stress curl spectrum is essentially white at low frequencies, the atmospheric forcing can be considered as stochastic. The SFCT model predicts the shape, the level, and the geographical variability of the SSH spectra resulting from the combination of local Ekman pumping and Rossby wave propagation from the eastern boundary quite well. However, the predictions do not hold in the region west of $6200 \mathrm{~km}\left(\approx 60^{\circ} \mathrm{E}\right.$; Fig. 8a), where the mean current speed becomes rather strong.

By using POP analysis, two distinct quasi-oscillatory (QO) modes of oceanic heat content variability with dominant periods of about 30 and 16 months were identified in the control experiment (Fig. 1). The 16-month QO mode was found in both the control and nonENSO experiments (Figs. 1 and 3), while the 30-month QO mode was only found in the control experiment. The more energetic 30-month QO mode can be identified as the ENSO response of the Indian Ocean. The less energetic 16-month QO mode can be considered as ENSO-independent since it appears in both experiments. The 16-month QO mode in the non-ENSO experiment was seen in the heat content but not in the atmosphere (Fig. 6b), thereby reflecting either a passive oceanic response to atmospheric forcing or weak coupling in the Indian Ocean. The question of what determines the dominant time scale of the less energetic ENSO independent QO mode was considered. The analysis suggests that the dominant time scale is given by the time a long Rossby wave requires to propagate across the effective width of the basin. Thus, the mode can be considered as a fetch-limited baroclinic mode response. Like the 30-month QO mode, the 16-month QO mode in its imaginary part phase has similar spatial scales and is related to negative SST anomalies and to anomalous equatorial easterlies in the equatorial eastern Indian Ocean and anomalous southeasterlies in the southeastern Indian Ocean. These anomalous wind stresses are the major forcing for the tropical SIO Rossby waves (Xie et al. 2002).

The close relationship between negative SST anomalies in the equatorial eastern Indian Ocean and anomalous easterly winds together with positive equatorial SST anomalies in the west lead Saji et al. (1999) and Webster et al. (1999) to hypothesize that these anomalies are part of a temporally oscillatory coupled dipole mode that involves some positive air-sea feedback, is independent of ENSO and acts at interannual time scales. In the present study, no evidence of a statistically significant ENSO-independent interannual peak in the wind stress curl spectra (Fig. 6b) and in equatorial wind stress (not shown) could be found when using spectral analysis. Thus, the feedback implied in the equatorial SST dipole must be very weak, and the 16month QO mode should not be significantly more energetic in the ocean interior than expected from the stochastic forcing approach presented here. It remains 


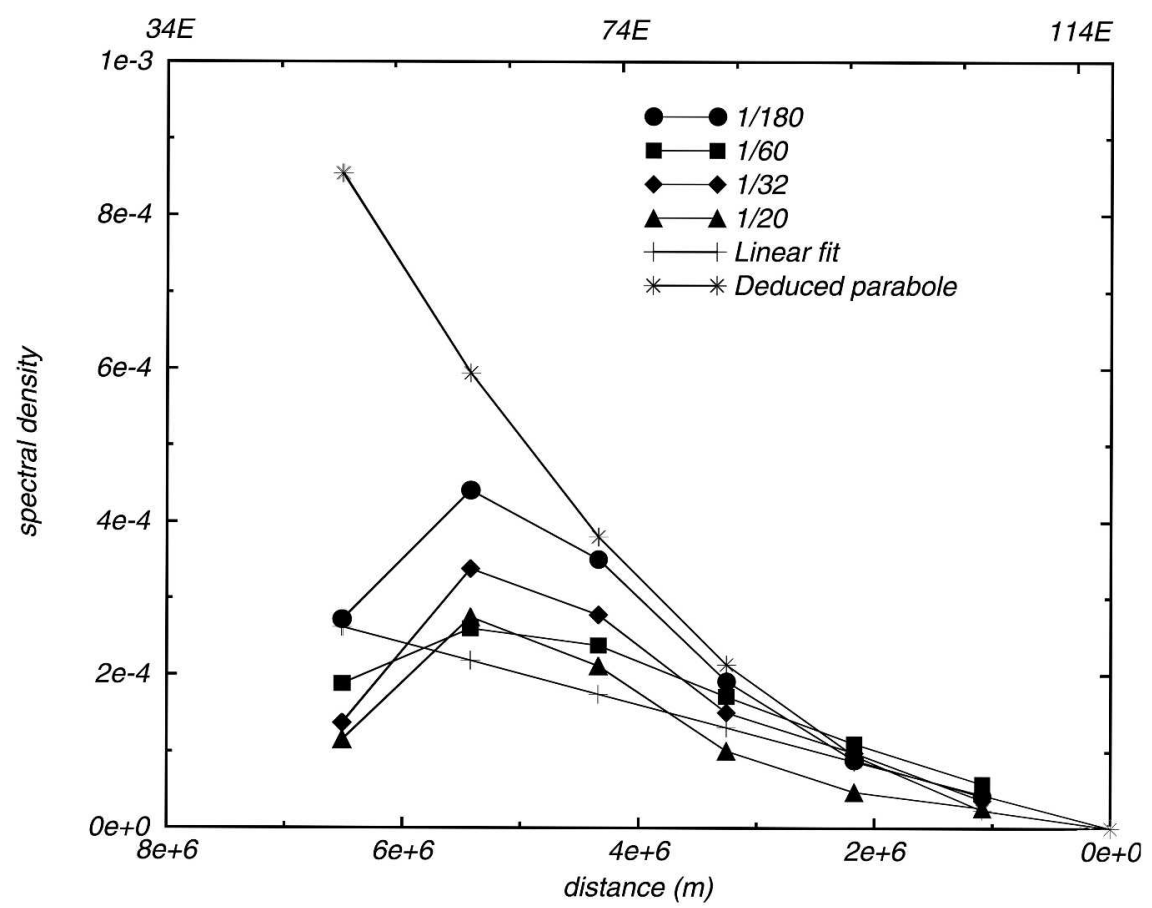

FIG. 9. Spectral power of sea surface height anomalies at $10^{\circ} \mathrm{S}$ in four frequency bands centered about 1/20,1/32,1/60, and 1/180 $\left(\right.$ month $\left.^{-1}\right)$ as a function of the distance from the eastern boundary, which is located at $110^{\circ} \mathrm{E}$. Sea surface height anomalies are from the non-ENSO experiment. The straight line is obtained from a best linear fit and the parabola is deduced from the straight line as indicated in the text. Note that the upper $x$-axis label indicates longitude.

to be shown what fraction of the observed oceanic variability can be explained by stochastic forcing.

\section{Comparison with observed data}

The data used are the daily wind stress from the European Centre for Medium-Range Weather Forecasts reanalysis for the period 1979-93 (Gibson et al. 1999; ERA-15) and the daily sea level at Cocos Island located in the southeastern Indian Ocean for the period 19862002 supplied by the National Tidal Facility, The Flinders University of South Australia (the data are available from the University of Hawaii Sea Level Center Web site at http://ilikai.soest.hawaii.edu/uhslc/). For both the wind stress and sea level fields, the first two harmonics of the annual cycle are calculated and the interannual anomalies are computed as the difference from those. For both fields the local linear trend was subtracted from the anomalies and then monthly means were calculated for the wind stress anomalies.

\section{a. Wind stress spectra}

The frequency spectra of ERA-15 zonal wind stress (Taux) at two locations along $0.5^{\circ} \mathrm{S}$ are shown in Fig. 10a. One location is in the Pacific at $100^{\circ} \mathrm{W}$ and the other one is in the Indian Ocean at longitude $100^{\circ} \mathrm{E}$. Both spectra have a peak of enhanced variability at the frequency (60 month) ${ }^{-1}$, which corresponds to a main ENSO period reported by many authors (e.g., Latif et al. 2001). These peaks reveal that, associated with ENSO, there is an oscillatory behavior in Taux not only in the eastern Pacific but also in the eastern Indian

TABLE 1. Values for the theoretical predictions.

\begin{tabular}{|c|c|c|}
\hline & Non-ENSO experiment $\left(10^{\circ} \mathrm{S}\right)$ & Cocos Island $\left(12^{\circ} \mathrm{S}, 96^{\circ} \mathrm{E}\right)$ \\
\hline $\begin{array}{l}\text { Baroclinic mode } \\
\text { Forcing }\end{array}$ & $\begin{aligned} f & =2.5 \times 10^{-5} \mathrm{~s}^{-1} \\
\beta & =2.25 \times 10^{-11}(\mathrm{~m} \mathrm{~s})^{-1} \\
A_{h} & =2.5 \times 10^{3} \mathrm{~m}^{2} \mathrm{~s}^{-1} \\
c_{b} & =1.4 \times 10^{-1} \mathrm{~m} \mathrm{~s}^{-1} \\
S_{0} & =7.5 \times 10^{-19} \mathrm{~m}^{2} \mathrm{~s}^{-2}(\text { cycles per month })^{-1}\end{aligned}$ & $\begin{aligned} f & =3.0 \times 10^{-5} \mathrm{~s}^{-1} \\
\beta & =2.2275 \times 10^{-11}(\mathrm{~m} \mathrm{~s})^{-1} \\
A_{h} & =2.5 \times 10^{3} \mathrm{~m}^{2} \mathrm{~s}^{-1} \\
c_{b} & =1.4 \times 10^{-1} \mathrm{~m} \mathrm{~s}^{-1} \\
S_{0} & =9.75 \times 10^{-19} \mathrm{~m}^{2} \mathrm{~s}^{-2}(\text { cycles per month })^{-1}\end{aligned}$ \\
\hline
\end{tabular}


a) Taux/ lats. $0.5^{\circ} \mathrm{S}$

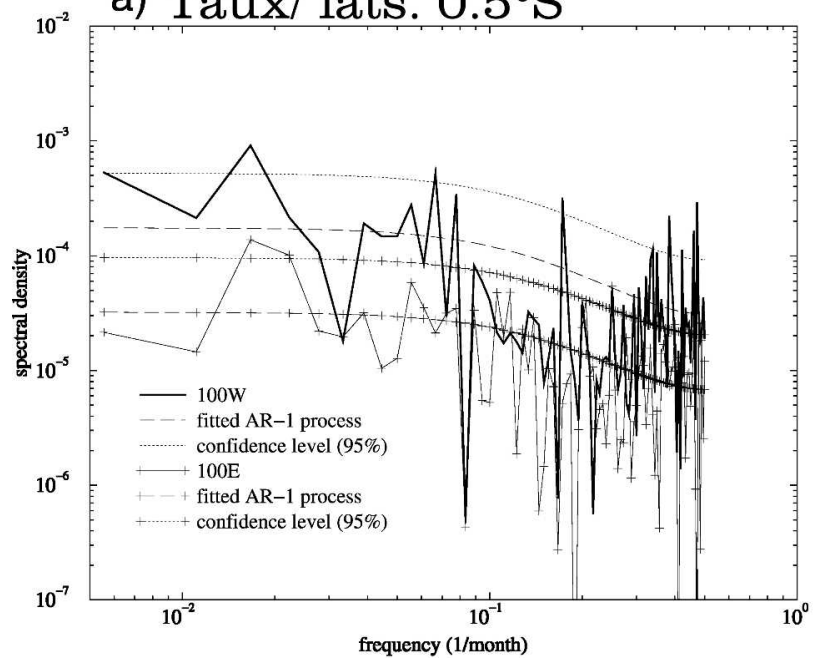

b) WSC/ lats. $12^{\circ} \mathrm{S}$ and $0.5^{\circ} \mathrm{S}$

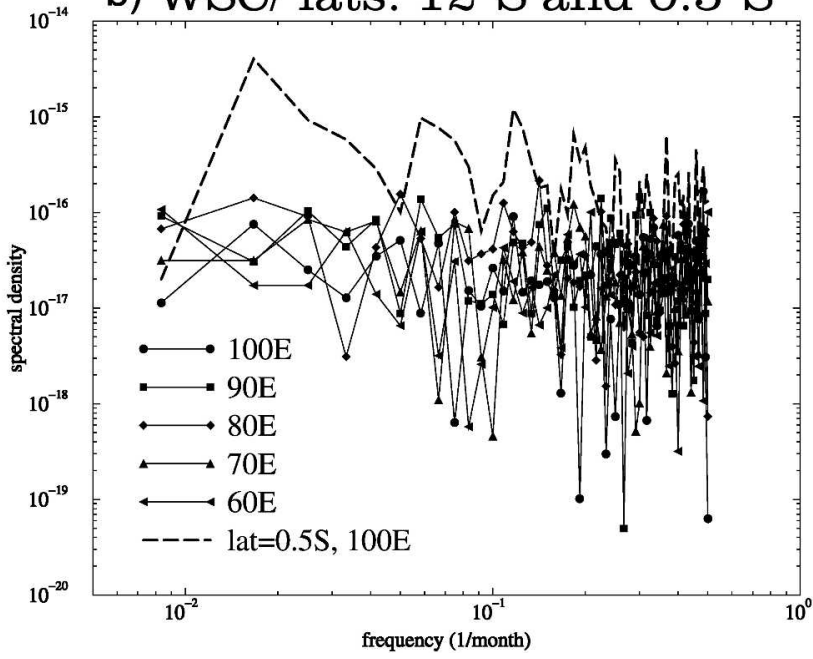

FIG. 10. (a) Frequency spectrum of zonal wind stress (Taux) along $0.5^{\circ} \mathrm{S}$ at longitudes $100^{\circ} \mathrm{E}$ and $100^{\circ} \mathrm{W}$. (b) Frequency spectra of wind stress curl (WSC) at $0.5^{\circ} \mathrm{S}, 100^{\circ} \mathrm{E}$, and along $12^{\circ} \mathrm{S}$ at various longitudes. Wind stress anomalies are from the ERA-15 reanalysis.

Ocean. This results from the Southern Oscillation, the atmospheric component of ENSO, which drives anomalies over the entire Indo-Pacific region. The spectrum at $100^{\circ} \mathrm{W}$ also shows an interannual peak at frequencies around $(16 \text { month })^{-1}$. This peak could be part of the biennial component of ENSO variability found by Rasmusson et al. (1990). However, the period is rather short.

Figure 10b shows the frequency spectra of WSC anomalies at $0.5^{\circ} \mathrm{S}$ and $100^{\circ} \mathrm{E}$ and along $12^{\circ} \mathrm{S}$ at various longitudes. The focus is put on WSC anomalies at $12^{\circ} \mathrm{S}$, since comparisons with the sea level at Cocos Island will be presented below. Associated with the ENSOrelated Taux peak at $100^{\circ} \mathrm{E}$ (Fig. 10a) there is a peak in the WSC at the same location at the frequency (60 month) $)^{-1}$ (dashed curve in Fig. 10b). This is consistent with an ENSO related oscillatory forcing of Rossby waves in the SIO through anomalous wind stress in the equatorial and near-equatorial Indian Ocean region.

The ENSO related wind stress anomalies extend over a band of latitudes in the Indian Ocean. In the control experiment described above, for instance, the highest correlations of zonal and meridional wind stress anomalies with the Niño-3 index are found between $5^{\circ} \mathrm{N}$ and $10^{\circ} \mathrm{S}$ (not shown). The frequency spectra for WSC anomalies along $12^{\circ} \mathrm{S}$ are essentially white (Fig. $10 \mathrm{~b}$ ) and the average white noise level is approximately 10 times smaller than the average level for WSC anomalies at $0.5^{\circ} \mathrm{S}$ and $100^{\circ} \mathrm{E}$. Since the WSC along $12^{\circ} \mathrm{S}$ is white the basic condition of the SFCZ model is satisfied.

The average white noise level at $10^{\circ} \mathrm{S}$ in the ERA-15 dataset is about 1.3 times the level occurring in the non-ENSO experiment (Fig. 6b). Correspondingly, $S_{0}$ should be 1.3 times as large and the oceanic response should also be larger than in the non-ENSO experi- ment. Thus, for $12^{\circ} \mathrm{S}$ an estimate of $S_{0}$ is $9.75 \times 10^{-19}$ $\mathrm{m}^{2} \mathrm{~s}^{-2}$ (cycles per month) ${ }^{-1}$.

\section{b. Sea level at Cocos Island}

For the tropical SIO, only few oceanic time series long enough to estimate power spectra at interannual frequencies are available. However, the $17 \mathrm{yr}$ of observations at Cocos Island $\left(12^{\circ} \mathrm{S}, 96.5^{\circ} \mathrm{E}\right)$ allow a quantitative comparison to the theoretical predictions of the stochastic model for the baroclinic response. Given the location of Cocos Island, the stochastic model should hold. The corresponding fetch for Cocos Island is $x=$ $1525 \mathrm{~km}$. Since the WSC power for the observations is larger than in the non-ENSO experiment, the power spectrum for the sea level at Cocos Island is expected to have a larger energy level than that corresponding to the same fetch in the non-ENSO experiment.

Figure 11 shows that the sea level frequency spectrum is red and decays approximately as $w^{-2.28}$ at periods less than 5 months. The prediction [integration of Eq. (8) with $S_{F}$ such as in Eq. (11)] calculated with the values from Table 1 matches well the slope at high frequencies. However, the energy level is underestimated by the predictions.

In a study about the low-frequency temperature fluctuations off Bermuda, Frankignoul (1981) found that excess energy at high frequency was likely due to data noise and eddy contamination. We speculate that the excess energy in the Cocos Island observations at high frequency could be also due to eddy contamination. The good agreement of the slope suggests that the flattening at low frequencies is due to the limited distance to the eastern boundary.

In summary, the stochastic model suggests that the interannual variability at Cocos Island is to a large extent caused by stochastic wind stress forcing. It remains 


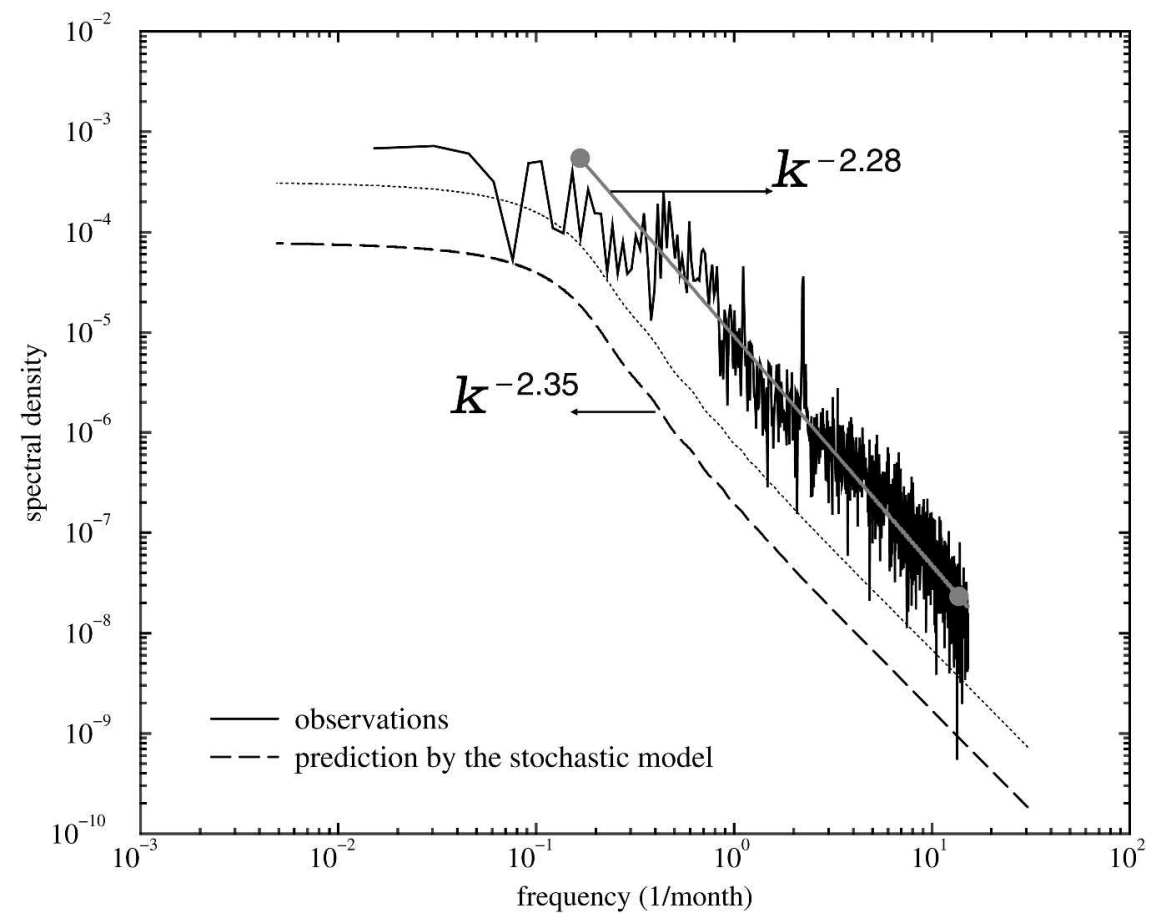

FIG. 11. Frequency spectrum of sea level at Cocos Island. Solid black line: spectrum of the sea level data for Cocos Island supplied by the National Tidal Facility, The Flinders University of South Australia. Dashed black line: prediction with the SFCT model with the parameter values listed in Table 1. Dotted black line: prediction with the SFCT model when $S_{0}$ is multiplied by a factor of 4 . Solid gray line: best linear fit of the spectrum of sea level at Cocos Island at high frequencies.

to be determined, however, whether the underestimation of the observed spectra can be attributed to poor parameter choices.

\section{Energy propagation from the equatorial Pacific to the southern Indian Ocean}

Potemra (2001) showed in a study with a reducedgravity model that Rossby waves generated in the equatorial Pacific by anomalous wind stress curl, upon reaching the western boundary of the Pacific, create poleward-propagating coastal Kelvin waves along the western coast of Australia, which in their turn generate offshore Rossby waves that can propagate into the interior Indian Ocean. The frequencies of the WSC forcing that allow the generation of offshore Rossby waves in the Indian Ocean are of order of several months to a year. Potemra (2001) also showed that, at interannual time scales, Rossby waves in the Pacific such as those generated during ENSO extremes mostly get reflected at the western boundary.

In this section, attention is paid to the $\mathrm{HC}$ variability in the southern part of the tropical Indian Ocean, with focus on the western coast of Australia. The objective is to examine if the transmission of energy from the tropical Pacific to the Indian Ocean as proposed by Potemra
(2001) works in the model and to investigate the influence of ENSO in such transmission. To accomplish the objective, a POP analysis is performed for HC anomalies in the region $10^{\circ}-30^{\circ} \mathrm{S}$ and $40^{\circ}-140^{\circ} \mathrm{E}$ which represents the southern part of the tropical Indian Ocean.

For both the control and non-ENSO experiments, the POP analyses reveal two dominant QO modes. One mode is associated with an annual time scale and the other with an interannual time scale. The POP pairs for both experiments are reminiscent of a westward-propagating signal that can be identified as Rossby wave propagation. The annual QO mode (Figs. 12a and 13a) has an $e$-folding time of 13 months (11 months) and explains $7 \%$ ( $8 \%$ ) of the variance in the control experiment (non-ENSO experiment). The cross spectral analysis of $z^{R}$ and $z^{I}$ of all these POP pairs - that is, the annual and the interannual POP modes for both the control and non-ENSO experiments (not shown) show that the variance of $z^{R}$ and $z^{I}$ is about the same and has a maximum around the POP frequency. Furthermore, for each POP,$z^{R}$ and $z^{I}$ have a phase shift of $-90^{\circ}$ and the coherence is also well above the $99 \%$ coherence squared level, as expected theoretically.

The annual QO mode in the southern part of the tropical Indian Ocean was not obtained in the POP analyses for the region including also the zone north of 
a) pop1 imaginary part $\left(p_{1}^{I}\right)$

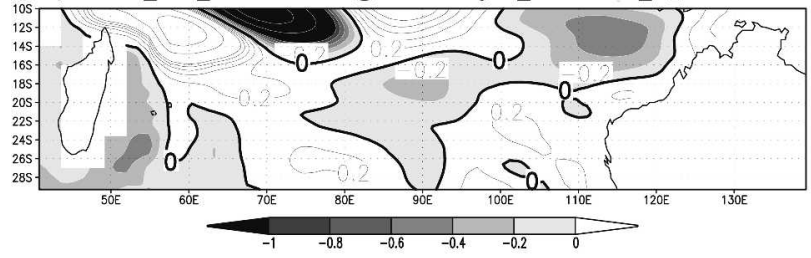

b) pop2 imaginary part $\left(p_{2}^{I}\right)$

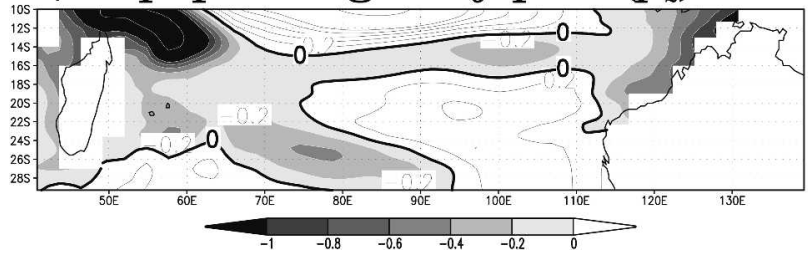

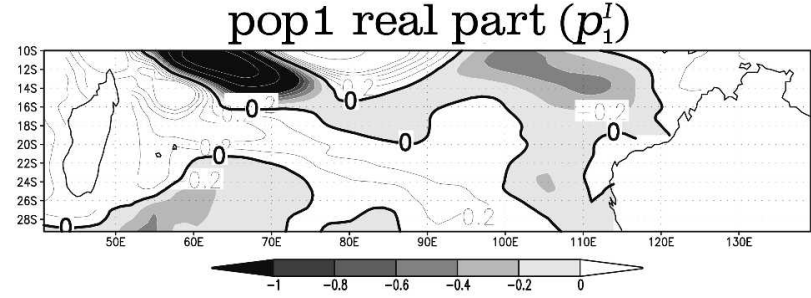

pop2 real part $\left(p_{2}^{I}\right)$

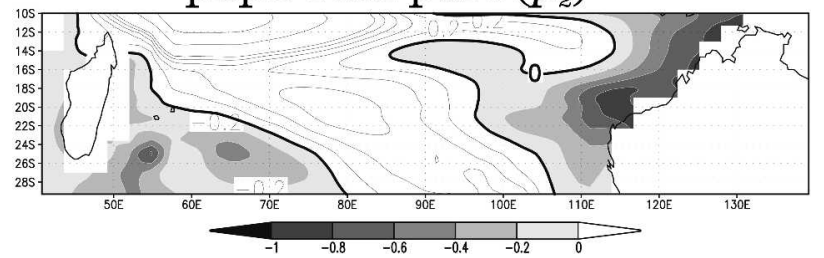

FIG. 12. Dominant POPs of HC anomalies in the SIO simulated in the control experiment: (a) pop1 and (b) pop2. Pop1 has a period of 13 months and explained variance of $7.4 \%$. Pop2 has a period of 31.5 months and explained variance of $20.6 \%$. Pop 1 is the annual POP and pop2 is ENSO related. The spatial domain for this POP analysis is the southern part of the tropical Indian Ocean. Contour intervals are $0, \pm 0.2, \pm 0.4, \pm 0.6, \pm 0.8, \pm 1, \pm 2, \pm 3$, and \pm 4 . Shaded areas denote negative values. In (a) and (b), the imaginary part is on the left and the real part is on the right.

$10^{\circ} \mathrm{S}$ shown in section 3 (Figs. 1 and 3 ). The reason for this could be that the inclusion of the zone north of $10^{\circ} \mathrm{S}$ gives more statistical weight to the equatorial processes and therefore to the semiannual time scale in comparison with the annual time scale.

At interannual time scales, the POP analyses for the southern part of the tropical Indian Ocean yield a QO mode for both experiments (Figs. 12b and 13b). However, the characteristics of the interannual POP pair in the control experiment differ from those of the POP pair in the non-ENSO experiment. For the control experiment (non-ENSO experiment), the interannual POP pair has a period of 31.5 months (21 months) and an $e$-folding time of 16 months (10.5 months) and explains $21 \%(12 \%)$ of the variance. The interannual POP pair in the control experiment is associated with the ENSO phenomenon. For the control experiment, the correlation of the Niño-3 index with the two time series $z_{2}^{R}$ and $z_{2}^{I}$ from the pop2 pair (Fig. 12b) amounts to 0.71 when Niño-3 leads $z_{2}^{I}$ by 5 months and to 0.71 when Niño-3 leads $z_{2}^{R}$ by 1 month. The pop 2 pair for the southern part of the tropical Indian Ocean can be also associated with the pop2 for the whole tropical Indian Ocean region (Fig. 1b). The correlation between the two $z_{2}^{R}$ time series for these two POPs is 0.8 .

The interannual POP pair in the non-ENSO experi-

\section{a) pop1' imaginary part $\left(p_{1}^{I^{\prime}}\right)$}

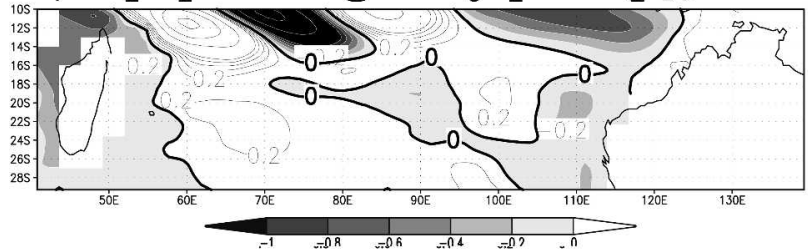

\section{b) pop2' imaginary part $\left(p_{2}^{I^{\prime}}\right)$}

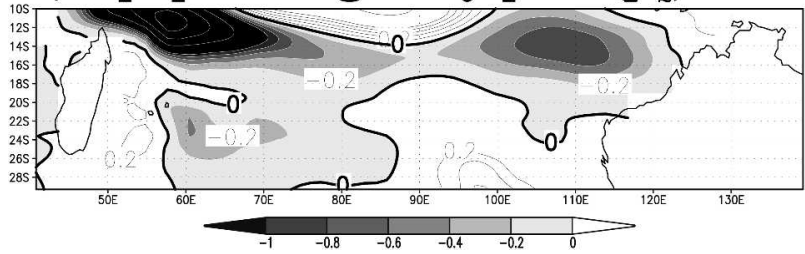

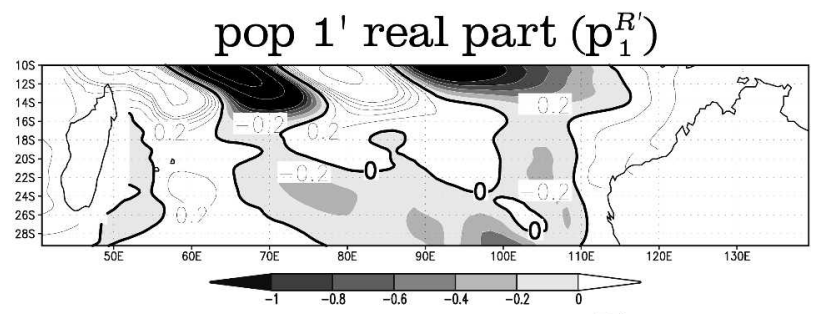

pop2' real part $\left(p_{2}^{R^{\prime}}\right)$

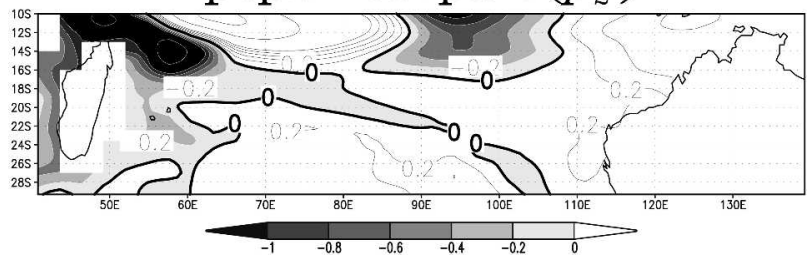

FIG. 13. Dominant POPs of HC anomalies in the SIO simulated in the non-ENSO experiment: (a) pop1' and (b) pop2'. Pop1' has a period of 11.5 months and explained variance of $7.8 \%$. Pop2' has a period of 21 months and explained variance of $12 \%$. Pop $1^{\prime}$ is the annual POP and pop2' is the interannual POP. The spatial domain for this POP analysis is the southern part of the tropical Indian Ocean. Contour intervals are $0, \pm 0.2, \pm 0.4, \pm 0.6, \pm 0.8, \pm 1, \pm 2, \pm 3$, and \pm 4 . Shaded areas denote negative values. In (a) and (b), the imaginary part is on the left and the real part is on the right. 


\section{a) Local explained variance by pop1}

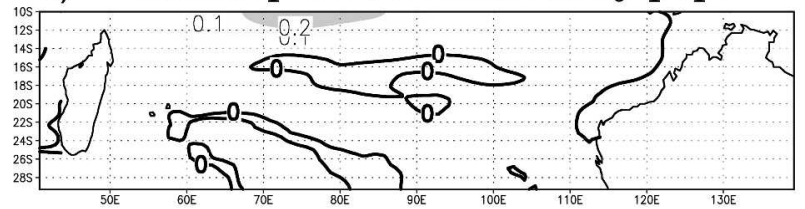

\section{b) Local explained variance by pop2}

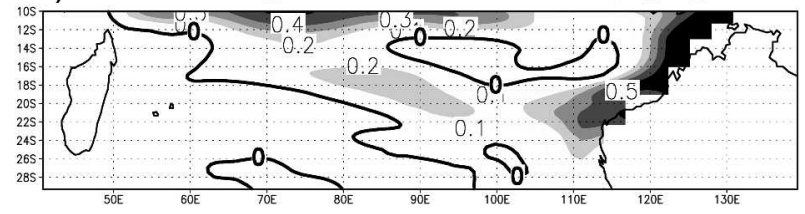

FIG. 14. Local variance explained by the POP pairs for the control experiment shown in Fig. 12. (a) Local variance explained by pop1 and (b) local variance explained by pop2. Only positive values are shown. Contour interval is 0.1 .

ment (Fig. 13b) is associated with the pop1' pair for the whole tropical Indian Ocean (Fig. 3a). The spatial patterns of both interannual POP pairs look similar and the correlation between both $z^{R}$ time series is 0.7 .

For both experiments, the annual QO mode shows significant $\mathrm{HC}$ anomalies confined to the north of $18^{\circ} \mathrm{S}$ (Figs. 12a and 13a). There is an asymmetry in the zonal distribution of these anomalies. While significant $\mathrm{HC}$ anomalies are located west of $110^{\circ} \mathrm{E}, \mathrm{HC}$ anomalies east of $110^{\circ} \mathrm{E}$ are up to $1 / 10$ as large. This suggests that Rossby waves are mainly produced by processes in the interior of the Indian Ocean basin at the annual time scale. The annual QO mode explains up to 20\% (Figs. $14 \mathrm{a}$ and 15a) of the variance in the region located between $10^{\circ}$ and $14^{\circ} \mathrm{S}$ and $60^{\circ}$ and $110^{\circ} \mathrm{E}$. Thus, although the annual QO mode for both experiments shows some indication of coastal Kelvin waves along the northwestern coast of Australia, these coastal Kelvin waves seem not to play an important role in either the creation or the enhancement of offshore Rossby waves in the southern part of the tropical Indian Ocean at the annual time scale.

Both the ENSO related QO mode in the control experiment and the interannual QO mode in the nonENSO experiment (Figs. 12b and 13b) also show higher anomalies to the west of $110^{\circ} \mathrm{E}$ than to the east of $110^{\circ} \mathrm{E}$. The interannual QO mode in the non-ENSO experiment explains up to $20 \%$ of the variance in the region between $10^{\circ}$ and $14^{\circ} \mathrm{S}$ and $60^{\circ}$ and $100^{\circ} \mathrm{E}$ (Fig. $15 \mathrm{~b})$. Over the same band of latitudes but east of $100^{\circ} \mathrm{E}$ this QO mode explains up to $10 \%$ of the variance. In contrast, the ENSO related mode explains more variance along the western coast of Australia: it explains up to $20 \%$ of the variance for the zone between $16^{\circ}$ and $26^{\circ} \mathrm{S}$ and up to $60 \%$ of the variance for the zone between $10^{\circ}$ and $16^{\circ} \mathrm{S}$ (Fig. 14b). The ENSO related mode explains up to $20 \%$ of the variance in the interior of the basin, in the region between $16^{\circ}$ and $21^{\circ} \mathrm{S}$ and $75^{\circ}$ and $95^{\circ} \mathrm{E}$. a) Local explained variance by pop1'

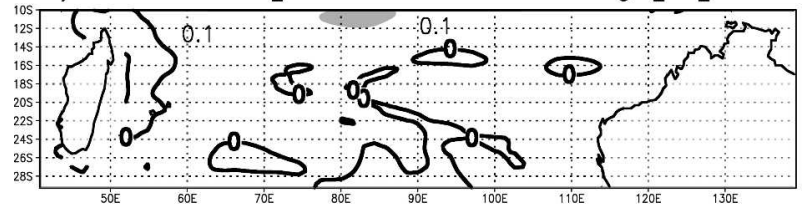

b) Local explained variance by pop2'

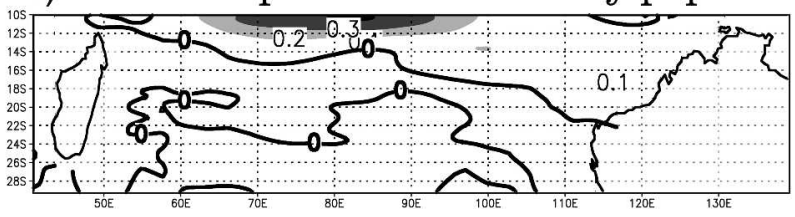

FIG. 15. Local variance explained by the POP pairs for the non-ENSO experiment shown in Fig. 13. (a) Local variance explained by pop1' and (b) local variance explained by pop2'. Only positive values are shown. Contour interval is 0.1 .

The spatial structure of the $\mathrm{HC}$ anomalies along the western coast of Australia for both the annual and interannual QO modes (Figs. 12 and 13) suggests that HC variability in the Indian Ocean east of $110^{\circ} \mathrm{E}$ could be due, at least partly, to the transmission of energy from the Pacific, due to poleward-propagating coastal Kelvin waves along the western coast of Australia. The highest contribution of the coastal Kelvin waves to the $\mathrm{HC}$ variability along the western coast of Australia and to the generation of offshore Rossby waves in the region that stretches from $16^{\circ}$ to $21^{\circ} \mathrm{S}$ is associated with ENSO (Fig. 14b). The interannual QO mode in the non-ENSO experiment (Fig. 15b) also shows some contribution to the $\mathrm{HC}$ variability in the region east of $110^{\circ} \mathrm{E}$ (up to $10 \%)$. In contrast, the annual mode appearing in both experiments does not explain variance east of $110^{\circ} \mathrm{E}$ (Figs. 14a and 15a), even though its spatial structure depicts coastal Kelvin waves propagating along the western coast of Australia. The generation of offshore Rossby waves by the coastal Kelvin waves along the western coast of Australia at interannual time scales and in particular at the ENSO time scale is not foreseen by the model predictions in Potemra (2001), which predicts the generation at time scales of the order of several months to a year.

In summary, it is confirmed that transmission of energy from the Pacific to the Indian Ocean occurs through coastal Kelvin waves along the western coast of Australia, as shown by Potemra (2001). In the ECHO-G model, this transmission occurs both at the annual time scale and at interannual time scales. At the annual time scale, the $\mathrm{HC}$ anomalies do not explain much variance east of $100^{\circ} \mathrm{E}$, especially not along the western coast of Australia. Thus, the coastal Kelvin waves seem not to play a significant role at the annual time scale.

At interannual time scales, the role of the waves in explaining variance along the western coast of Austra- 
lia increases. The $\mathrm{HC}$ anomalies associated with both ENSO-independent and ENSO-related coastal Kelvin waves are locally important for the region east of $110^{\circ} \mathrm{E}$. In the case of ENSO-related coastal Kelvin waves, they are also important for the generation of offshore Rossby waves in the region that stretches from $16^{\circ}$ to $21^{\circ} \mathrm{S}$ and therefore they are also important for the $\mathrm{HC}$ variability in the interior of the basin at these latitudes. North of $16^{\circ} \mathrm{S}$, the much stronger HC anomalies away from the coast of Australia suggest that they are generated mainly by processes in the interior of the Indian Ocean.

\section{Conclusions}

In the present study, a simple stochastic forcing model was used to explain the interannual variability in the tropical south Indian Ocean. The model is an extension of the Frankignoul et al. (1997) formulation by Sirven et al. (2002) and has been adapted in the present study to describe the case when wind stress curl decays at high wavenumbers as $k^{-3}$. In the SFCT model, the baroclinic variability is simulated using the equation for long nondispersive Rossby waves forced by wind stress curl fluctuations. The wind stress is assumed to be stochastic with a white frequency spectrum. Therefore the oceanic response represents the continuous excitation of the ocean interior by short time-scale weather fluctuations. The model considers zonally dependent forcing and dissipation and takes into account the effect of the mean flow. At each frequency, the baroclinic response consists of a forced response plus a Rossby wave generated at the eastern boundary. The analysis presented in this paper is statistical and based on data from the control and non-ENSO experiments with the ECHO-G model, wind stress data from the ERA-15 reanalysis, and observational sea level data at Cocos Island. The model predicts the shape and level of the response frequency spectra and their variation with longitude and latitude.

The stochastic model predicts a spectrum with a highfrequency $w^{-\alpha}$ decay, where $\alpha$ is a positive constant (2 $<\alpha<3$ ) that levels off at low frequencies to a constant value. This is also the shape seen in the spectra for the non-ENSO experiment. Furthermore, the SFCT model correctly predicts how this spectral shape changes with longitude as a result of the varying fetch and wind stress field intensity.

Although the baroclinic response is spread over a continuum of frequencies, it can be associated with a dominant time scale that is given by the time a long baroclinic Rossby wave requires to propagate across the basin and that increases with the effective width of the basin. The stochastic model predictions for a temporally white wind stress curl spectrum are also broadly consistent with the shape and level of frequency spectra of sea level measured at Cocos Island. This suggests that the stochastic model is an appropriate starting point for understanding interannual changes in the real ocean in the SIO region that are independent of ENSO in the Pacific, and in general, independent of the interannual variability in the Pacific Ocean region. On the other hand, based on the data from ERA-15 reanalysis and both experiments with ECHO-G, the present study provides evidence that the ENSO signature in the SIO region includes an oscillatory wind stress curl forcing in the east with a period corresponding to the dominant ENSO period.

With respect to the transmission of energy from the tropical Pacific to the southern Indian Ocean, our results confirm that transmission occurs through coastal Kelvin waves along the western coast of Australia, as shown by Potemra (2001). In the two experiments with the ECHO-G model, this transmission occurs both at the annual time scale and at interannual time scales. Generation of offshore Rossby waves by these coastal Kelvin waves at interannual time scales and in particular at the ENSO time scale was found, which is not foreseen by the model predictions in Potemra (2001). We also found that at interannual time scales the coastal Kelvin waves are locally important for the region east of $110^{\circ} \mathrm{E}$. In the case of ENSO-related coastal Kelvin waves, they are also important for the generation of offshore Rossby waves in the region that stretches from $16^{\circ}$ to $21^{\circ} \mathrm{S}$. North of $16^{\circ} \mathrm{S}$, the stronger $\mathrm{HC}$ anomalies away from the coast of Australia suggest that they are generated mainly by processes in the interior of the Indian Ocean.

Acknowledgments. We thank Drs. Noel Keenlyside and Reiner Schnur for fruitful discussions. We also thank Dr. Stefan Hagemann, who contributed to improve an earlier version of this manuscript. Support from the "Francisco José de Caldas Institute for the Development of Science and Technology (COLCIENCIAS)" through its scholarship program (AB-B), from the German Ocean CLIVAR programme, and from the German DEKLIM project is gratefully acknowledged. The numerical integrations were performed at the Deutsches Klimarechenzentrum.

\section{REFERENCES}

Baquero-Bernal, A., M. Latif, and S. Legutke, 2002: On dipolelike variability of sea surface temperature in the tropical Indian Ocean. J. Climate, 15, 1358-1368.

Birol, F., and R. Morrow, 2001: Sources of the baroclinic waves in the southeast Indian Ocean. J. Geophys. Res., 106, 91459160.

Carton, J. A., G. Chepurin, X. Cao, and B. Giese, 2000: A simple data assimilation analysis of the global upper ocean 1950-95. Part I: Methodology. J. Phys. Oceanogr., 30, 840-858.

Chambers, D., B. D. Tapley, and R. H. Stewart, 1999: Anomalous warming in the Indian Ocean coincident with El Niño. $J$. Geophys. Res., 104, 3035-3047.

Frankignoul, C., 1981: Low-frequency temperature fluctuations off Bermuda. J. Geophys. Res., 86, 6522-6528. 
_ 1995 : Climate spectra and stochastic climate models. Application of Statistical Technique, Springer-Verlag, 29-51.

—, P. Müller, and E. Zorita, 1997: A simple model of the decadal response of the ocean to stochastic wind stress forcing. $J$. Phys. Oceanogr., 27, 1533-1546.

Gallagher, S., H. von Storch, R. Schnur, and G. Hannoschöck, 1991: The Pop manual (POPS = Principal Oscillation Patterns). German Climate Computer Centre (DKRZ) Tech. Rep. 1, 66 pp.

Gibson, J. K., P. Källberg, S. Uppala, A. Hernandez, A. Nomura, and E. Serrano, 1999: ERA-15 description, version 2. ECMWF Re-analysis Project Rep. Series 1, 73 pp.

Hasselmann, K., 1976: Stochastic climate models. Part I: Theory. Tellus, 28, 473-485.

_ 1988: PIPs and POPs: The reduction of complex dynamical systems using principal interaction and oscillation patterns. $J$. Geophys. Res., 93, 11 015-11021.

Holton, J. R., 1992: An Introduction to Dynamic Meteorology. Academic Press, 511 pp.

Jin, F.-F., 1997: A theory of interdecadal climate variability of the North Pacific ocean-atmosphere system. J. Climate, 10, 18211835.

Latif, M., and T. P. Barnett, 1994: Causes of decadal climate variability in the North Pacific/North American sector. Science, 266, 96-99.

— comparison project. Climate Dyn., 18, 255-276.

Legutke, S., and R. Voss, 1999: The Hamburg atmosphere-ocean coupled circulation model ECHO-G. German Climate Computer Centre (DKRZ) Tech. Rep. 18, 62 pp.

Masumoto, Y., and G. Meyers, 1998: Forced Rossby waves in the southern tropical Indian Ocean. J. Geophys. Res., 103, 27 589-27 602.

Perigaud, C., and P. Delecluse, 1993: Interannual sea level variations in the tropical Indian Ocean from Geosat and shallow water simulations. J. Phys. Oceanogr., 23, 1916-1934.

Potemra, J. T., 2001: Contribution of equatorial Pacific winds to southern tropical Indian Ocean Rossby waves. J. Geophys. Res., 106, 2407-2422.

Qiu, B., W. Miao, and P. Müller, 1997: Propagation and decay of forced and free baroclinic waves in off-equatorial oceans. $J$. Phys. Oceanogr., 27, 2405-2417.

Rasmusson, E., X. Wang, and C. F. Ropelewski, 1990: The biennial component of ENSO variability. J. Mar. Syst., 1, 71-96.

Roeckner, E., and Coauthors, 1996, The atmospheric general circulation model ECHAM4: Model description and simulation of present-day climate. Max-Planck Institut für Meteorologie Tech. Rep. 218, 90 pp.

Saji, N. H., B. Goswami, P. Vinayachandran, and T. Yamagata 1999: A dipole mode in the Indian Ocean. Nature, 401, 360363.

Schnur, R., G. Schmitz, N. Grieger, and H. von Storch, 1993 Normal modes of the atmosphere as estimated by principal oscillation patterns and derived from quasigeostrophic theory. J. Atmos. Sci., 50, 2386-2400.

Sirven, J., C. Frankignoul, G. de Coëtlogon, and V. Taillandier, 2002: Spectrum of wind-driven baroclinic fluctuations of the ocean in the midlatitudes. J. Phys. Oceanogr., 9, 104-127.

Sturges, W., and B. G. Hong, 1995: Wind forcing of the Atlantic thermocline along $32^{\circ} \mathrm{N}$ at low frequencies. J. Phys. Oceanogr., 25, 1706-1715.

Sura, P., F. Lunkheit, and K. Fraedrick, 2000: Decadal variability in a simplified wind-driven ocean model. J. Phys. Oceanogr., 30, 1917-1930.

Terray, L., S. Valcke, and A. Piacentini, 1998: The OASIS coupler user guide, version 2.2. CERFACS Tech. Rep. TR/CMGC/ 98-05, $77 \mathrm{pp}$

von Storch, H., T. Bruns, I. Fischer-Bruns, and K. Hasselmann, 1988: Principal oscillation pattern analysis of the 30-60 day oscillation in a GCM equatorial troposphere. J. Geophys. Res., 93, 11 022-11036.

Webster, P., A. Moore, J. Loschnigg, and R. Leben, 1999: Coupled ocean-atmosphere dynamics in the Indian Ocean during 1997-1998. Nature, 401, 356-360.

Wolff, J.-O., E. Maier-Reimer, and S. Legutke, 1997: The Hamburg Ocean Primitive Equation Model. German Climate Computer Centre (DKRZ) Tech. Rep. 13, 98 pp.

Xie, S.-P., H. Annamalai, F. A. Schott, and J. P. J. McCreary, 2002: Structure and mechanisms of south Indian Ocean climate variability. J. Climate 15, 864-878. 